\title{
Household Liquidity and Incremental Financing Decisions: Theory and Evidence*
}

\author{
M. Ricardo Cunha, Bart M. Lambrecht, and Grzegorz Pawlina \\ Forthcoming in Journal of Business Finance 83 Accounting
}

\begin{abstract}
In this paper we develop a stochastic model for household liquidity. In the model, the optimal liquidity policy takes the form of a liquidity range. Subsequently, we use the model to calibrate the upper bound of the predicted liquidity range. Equipped with knowledge about the relevant control barriers, we run a series of empirical tests on a panel data set of Dutch households covering the period 19922007. The results broadly validate our theoretical predictions that households $i$ ) exhaust most of their short-term liquid assets prior to increasing net debt, and ii) reduce outstanding net debt at the optimally selected upper liquidity barrier. However, a small minority of households appears to act sub-optimally. Poor and vulnerable households rely too frequently on expensive forms of credit (such as overdrafts) hereby incurring substantial amounts of fees and fixed borrowing costs. Elderly households and people on social benefits tend to accumulate too much liquidity. Finally, some households take on expensive short-term credit while having substantial amounts of low-yielding liquid assets.
\end{abstract}

\footnotetext{
${ }^{*}$ Cunha is from Catholic University of Portugal, Porto, and gratefully acknowledges financial support for his doctoral studies from Fundacao para a Ciencia e Tecnologia. Lambrecht and Pawlina are from Lancaster University Management School, and thank the ESRC (grant RES-062-23-0078) for financial support. In this paper use is made of data of the DNB Household Survey. Helpful comments received from the anonymous referee and the editor are kindly acknowledged. Correspondence can be sent to Grzegorz Pawlina (g.pawlina@lancaster.ac.uk), Department of Accounting and Finance, Lancaster University Management School, Lancaster LA1 4YX, UK.
} 


\section{Introduction}

Recent survey evidence by Meleis and Israel (2010) suggests that many US consumers feel that their financial affairs are simply out of control. A typical family uses checks, debit cards, credit cards, multiple accounts, automated teller machines and automated clearing house transactions. Spending is harder to control than ever before because multiple household members write checks and make debit card purchases against the same account, increasing the risk of overdrafts. For a typical household the volume of transactions has doubled over the last few decades, and "so great is the concern about juggling monthly payments and avoiding overdrafts that many US households are now trapped into a compulsive routine of electronically verifying their account balances, often 30 to 50 times per month." These are, according to Meleis and Israel (2010), "symptoms of a much larger problem, which is cash management".

The recent economic crisis has exposed the gravity of the problem and the US government has recently issued a raft of legislation in order to protect consumers. For example, in November 2009 the Federal Reserve Board issued amendments to "Regulation E" that prohibit financial institutions from charging customers fees for paying overdrafts on ATM and one-time debit card transactions that overdraw a consumer's account, unless a consumer consents or opts in to be charged a fee for these type of transactions 1

In a similar vein Chairman Ben Bernanke of the Federal Reserve announced in December 2008 revised rules concerning credit cards that "represent the most comprehensive and sweeping reforms ever adopted by the Board for credit card accounts. These protections will allow consumers to access credit on terms that are fair and more easily understood... Consumers must understand the pricing of credit card services if they are to make well informed, responsible decisions about the use of credit and the management of their accounts".

While these facts and quotes illustrate the importance of the household cash management problem, one must be cautious not to generalise. Households are not a homogenous group and the majority of households do not face serious problems. For example, a November 2008 FDIC study of Bank Overdraft Programs in the US found that $74 \%$ of consumers do not incur overdraft fees, $12 \%$ of consumers are infrequent overdraft users, $9 \%$ are moderate users and $5 \%$ are considered heavy overdraft users. The average annual fee amount incurred by heavy users is $\$ 1610$. The study shows that a small minority of households pay the bulk of overdraft fees charged by banks.

\footnotetext{
${ }^{1}$ The Electronic Fund Act was passed by US Congress in 1978 to establish the rights and liabilities of consumers as well as the responsibilities of all participants in electronic fund transfer activities. The act was implemented in Federal Reserve Board "Regulation E".
} 
The nonprofit Center for Responsible Lending (CRL) says that those with frequently overdrawn accounts are among the most financially vulnerable as they tend to be lower income, single, non-white and rent their homes. The CRL also labels overdrafts as "the highest cost credit banks offer" and accuses some banks from engaging in unfair strategies in order to maximise income from overdraft charges as evidenced by a recent court ruling against Wells Fargo (Newsweek, August 13, 2010) $\mathrm{L}^{2}$

Given the high charges for overdrafts, credit cards or credit offered by retailers, one might wonder why some consumers use these forms of credit and do not rely on cheaper financing sources. One possible explanation is that some households make decisions that are sub-optimal from a financial viewpoint. Campbell (2006) claims that "many households invest effectively, but a minority make significant mistakes". According to Campbell (2006) this minority appears to be poorer and less well educated $\mathrm{H}^{3}$

Despite it apparent importance, the existing household finance literature has largely ignored the study of household cash management, and household liquidity more generally. Instead the focus has primarily been on the decision of the optimal composition of the financial investments of the household, the efficiency of household portfolios, and the role of diversification (see Campbell (2006)) $4^{4}$ In this paper we aim to address this gap by analysing the dynamics of household liquidity, and the implications of these dynamics for the financing decisions of households. In the concluding section we also discuss the implications of our results for the policies and strategies of lenders and financial regulators.

Households hold cash and other liquid assets for two main motives (Keynes (1936)): a transaction motive and a precautionary motive. In the latter case cash holdings have the function of a "safety net", whereas in the former case cash allows for the smooth execution of everyday financial transactions.

The determination of optimal cash and liquid asset levels has been analysed in the literature as the balancing of two main driving forces - the benefits and the costs of holding these assets - and the existing literature relies mostly on inventory optimisation approaches. According to these models, cash must be held up to the level where the marginal benefits of liquid holdings equal the marginal costs. Santomero (1974) develops a general model of the demand for liquid assets by households, considering different short-term assets and specific rates of return and transaction costs for each

\footnotetext{
${ }^{2}$ In August 2010 a federal judge in California ordered Wells Fargo to pay $\$ 230$ million to consumers in the state who overdrafted after the bank engaged in "high-to-low resequencing", recording debt transactions from highest amount to lowest, triggering multiple charges.

${ }^{3}$ The mistakes come in a variety of forms such as nonparticipation in risky asset markets, underdiversification of risky portfolios, and failure to exercise options to refinance.

${ }^{4}$ For a detailed analysis of household portfolios (focused on asset allocation) and for an international comparison see Guiso, Haliassos, and Jappelli (2002).
} 
asset type. His model, the first derived for household liquid assets, was inspired by the works of Baumol (1952) and Tobin (1956), and by the works of Miller and Orr (1966) and Whalen (1965) focusing on firm demand for money under uncertainty. Unlike our paper, Santomero (1974) does not focus on an empirical linkage between the household liquid asset holdings and its characteristics.

More recently, Eisfeldt (2007) analyses the demand for liquid assets arising from consumption smoothing purposes. Bolton and Rosenthal (2005) bring together a selection of papers most of which argue that many poor people live where traditional banking is not an option. This makes poor people susceptible to largely unregulated fringe banks and businesses that charge credit-starved borrowers high interest rates, fees and penalties. Agarwal et al. (2005) study whether consumers choose the right credit contracts. They find that on average consumers chose the contract that ex post minimised their net costs. However, a small minority of consumers persists in holding substantially sub-optimal contracts without switching. Zinman (2007) shows that many households borrow on credit cards at high rates while holding low-yielding bank account balances. While some of this may be due to irrational behaviour Zinman argues that the puzzle can largely be explained by the fact that bank deposits are more liquid and therefore have an implicit value. For example, many household expenditures (such as utility bills, home repairs and loan repayments) cannot be executed through credit cards. Finally, Stango and Zinman (2009) examine what people actually pay to use their checking and credit card accounts. They find that the median household pays $\$ 500$ per year and could avoid more than half these costs with minor changes in behaviour 5

We develop a household liquidity model that attempts rationally to explain household liquidity management. Under the optimal liquidity policy, households do not take any debt before internal funds are fully exhausted. When liquidity is exhausted households increase net debt (by borrowing or liquidating long-term financial assets) to restore liquidity to a strictly positive level. The optimality of a discrete increase in liquidity results from the fixed costs (such as fees or fixed transaction costs) associated with increasing net debt. If liquidity exceeds some upper threshold then it is optimal for the household to decrease net debt (by investing in long-term illiquid assets, or by paying off debt) by a discrete amount to some optimal interior liquidity level.

The objective of our paper is twofold. First, our model provides an empirical framework that allows quantifying certain parameters of liquidity decisions, such as (perceived) transaction costs of reducing or increasing net debt. Upon estimating

\footnotetext{
${ }^{5}$ Our paper can also be viewed as complementary to the empirical contributions on corporate cash holdings (such as Kim, Mauer, and Sherman (1998), Opler, Pinkowitz, Stulz, and Williamson (1999), Dittmar and Mahrt-Smith (2007), and Bates, Kahle, and Stulz (2009)).
} 
our empirical model using a panel data set of Dutch households covering the period 1992-2007, we are able to assess the significance of these parameters by inferring the shape of the underlying distribution of the households' liquidity level and by identifying lumpy changes in liquidity. The second purpose of our empirical tests is to establish whether household demand for liquidity is indeed driven by the trade-off between the interest forgone by holding low-yield short-term liquid assets and the costs of borrowing or liquidating illiquid assets when the household runs out of short-term liquidity. The alternative hypothesis is that household liquidity policy is determined by factors outside the model, such as the inability to make optimal or fully rational financing decisions. The answers to these research questions may have important policy implications for regulators and lenders.

One limitation of our theoretical model is that it does not explicitly differentiate between overdrafts and longer term debt, but instead pools the various classes of debt together. Incorporating overdrafts would substantially complicate the theoretical model ${ }^{6}$ Furthermore, we will show that introducing overdraft balances into (a modified version) of the empirical model is not all that helpful in explaining household liquidity for a number of reasons. First, only $7 \%$ of household-years include a positive overdraft balance. Second, these overdrafts are to be attributed to a very small minority of households (87.38\% of households in our sample never report an overdraft while $4.41 \%$ have an overdraft every year). It therefore appears that in the Netherlands (as in the US) only a small group of households rely on overdrafts. Third, rather than the amount of overdraft debt, what appears to be much more important for explaining household liquidity is the mere presence of overdrafts (i.e. whether or not a household has overdraft debt in the first place). In particular, our model for household liquidity works well for households that do not use overdrafts but it appears to be inconsistent with the liquidity policy of households that do have overdrafts. This suggests that the presence of overdrafts is symptomatic of sub-optimal financing decisions. Analysing the determinants of the probability of a household having an overdraft (using a probit model) we find that high leverage, a large number of children, being unemployed or a recipient of social benefits increases the likelihood of a household having an overdraft. This suggests that poorer and more vulnerable households are more likely to follow a suboptimal liquidity policy. In a similar vein, we find that elderly households and those receiving social benefits appear not adequately to reduce their levels of net debt when accumulating excess liquidity.

The remainder of the paper is organised as follows. The derivation of the stochastic liquidity model is presented in section 2. Section 3 contains the discussion of the

\footnotetext{
${ }^{6}$ Cash management models with overdrafts include Wirth (1984) and Bar-Ilan (1990).
} 
empirical methodology, whereas the data used is described in section 4 . The results of the empirical analysis are discussed in section 5. Finally, conclusions are presented in section 6 .

\section{A simple model}

Modelling household liquidity in all its complexity is a challenging task, particularly if one wants to capture the interaction between liquidity and financial decisions. For example, a household facing liquidity constraints might engage in additional parttime employment or increase the number of hours in the current job. Our theoretical model abstracts from such interactions and assumes that non-financial decisions are independent of liquidity management decisions.

The model of liquidity management we present is inspired by the stochastic inventory management literature, and by the works of Harrison and Taksar (1983) and Harrison, Sellke, and Taylor (1983) on the control of Brownian motion. In our model, the amount of liquid assets $L$ held by a household follows (when not controlled) an arithmetic Brownian motion:

$$
\mathrm{d} L=\mu \mathrm{d} t+\sigma \mathrm{d} z_{t},
$$

where $\mu$ is the drift rate, $\sigma$ is the variance and $\mathrm{d} z_{t}$ is a Wiener increment. The change in the amount of liquid assets at each instant can be interpreted as the difference between income and consumption..$^{7}$ A household can make three types of liquidity decisions. First, it can raise its level of net debt to increase the liquidity balance, $L$. Second, it can reduce the level of net borrowing, which would lead to the reduction of $L$. Finally, it can do nothing. The type of decision taken by a household results from the following trade-off. On the one hand, holding liquidity is costly as short-term liquid assets do not yield any interest, whereas long-term financial assets do. On the other hand, liquidity serves as a safety cushion reducing the costs of future borrowing or the costs if liquidating illiquid long-term assets.

Denote the household's subjective discount rate by $\delta$. The household faces a market interest rate $r$, which applies to both borrowing and investment in long-term illiquid financial assets (lending). This assumption implies that investment in long-term financial assets is equivalent to negative debt and, as a result, it is the amount of net

\footnotetext{
${ }^{7}$ Consequently, the process (1) reflects a situation in which income realizations at each instant $t$ are normally and independently distributed and consumption is either constant, proportional to the magnitude of the income shock at $t$ or, in general, normally distributed as well. In such a case, the resulting increments of liquidity are normally and independently distributed too and the (accumulated) liquidity follows an arithmetic Brownian motion. A detailed description of a possible framework and set of assumptions leading to equation (1) is presented in Appendix A.
} 
debt that matters. The fixed cost of increasing net debt (by issuing loans or liquidating long-term financial assets) is $K(\geq 0) .8$ The amount of borrowing, $L^{*}$, is selected optimally as a result of the tradeoff between its cost, $\frac{L^{*} r}{\delta}+K$, and its benefit, which is the reduction in the present value of the cost of any subsequent increases in net debt ${ }^{9}$ Obviously, when $K=0$, a household would just increase net debt infinitesimally every time liquidity is exhausted to avoid the costs of forgone interest. (For $r=0$ and $K>0$, the optimal amount of borrowing would be infinite.)

If the liquidity level is sufficiently high, a household may find it optimal to reduce the level of net debt (which is equivalent to investing excess funds in long-term financial assets or repaying existing debt). The associated fixed cost of such a reduction is $M \geq 0$. Consequently, each time the liquidity level hits upper barrier $\bar{L}$, a household optimally reduces it to the optimal target level $L^{*}<\bar{L} 10$ If there is no fixed cost of reducing the level of net debt (i.e., if $M=0$ ), then a household with excess cash makes no discrete changes in its liquidity level and uses only the amount in excess of the upper level $\bar{L}$ to reduce net debt ${ }^{11}$ Moreover, no investment in long-term financial nor debt repayment is ever made for $r=0$. Figure 1 presents a graphical representation of the liquidity management policy considered.

[Insert Figure 1 about here]

A strictly positive sum of $(K+M)$ is a necessary condition for holding liquidity and for the policy analysed in this section to be non-degenerate. A strictly positive interest rate precludes the existence of the trivial optimal policy of borrowing an infinite amount in order to avoid the fixed cost of future external financing rounds and ensures that reducing net debt is optimal for a sufficiently high level of liquidity.

\footnotetext{
${ }^{8}$ We implicitly assume that loans and long-term financial assets are identical in terms of their return, $r$, and transaction costs, $K$. This assumption may not strictly hold in reality, but is adopted to keep the model tractable.

${ }^{9}$ As there is no instantaneous convenience yield of holding liquidity, nor a time lag between the decision to borrow and the receipt of funds, the household does not optimally borrow until liquidity is fully exhausted. If we allowed for a time lag between the decision to borrow and the receipt of funds, borrowing would optimally take place for a strictly positive liquidity level. To find this level, we would have to specify a penalty associated with letting liquidity drop down to zero. Moreover, the model itself would become much less tractable without providing obvious additional insights. In the empirical part of the analysis, a strictly positive lower liquidity barrier would result in lower slope coefficients.

${ }^{10}$ Since the borrowing and lending rates are the same, liquidity is always reset to the same level irrespective whether resetting results from new borrowing or lending, see Harrison (1985).

${ }^{11}$ In such a case, barriers $\bar{L}$ and $L^{*}$ coincide.
} 
The value of liquidity from a household's perspective, $F(L)$, is equal to the difference of the present values of the interest on (net) long-term assets and the transaction costs discounted at a rate $\delta$. Given liquidity dynamics (1), the value of liquidity can be derived using standard dynamic programming techniques (see, e.g., Dixit (1993)). In general, $F(L)$ is given by

$$
F(L)=A_{1} e^{\beta_{1} L}+A_{2} e^{\beta_{2} L},
$$

where $A_{1}$ and $A_{2}$ are constants to be determined. Parameters $\beta_{1}$ and $\beta_{2}$ are the negative and positive root, respectively, of the following equation:

$$
\delta-\mu x-\frac{1}{2} \sigma^{2} x^{2}=0 .
$$

Consequently, the liquidity management problem boils down to finding barriers $L^{*}$ and $\bar{L}$ and constants $A_{1}$ and $A_{2}$ using the following system of boundary conditions for $F(L)$ :

$$
\begin{aligned}
F\left(L^{*}\right)-F(0) & =K+\frac{r L^{*}}{\delta}, \\
F(\bar{L})-F\left(L^{*}\right) & =\frac{r\left(\bar{L}-L^{*}\right)}{\delta}-M, \\
F^{\prime}\left(L^{*}\right) & =\frac{r}{\delta}, \\
F^{\prime}(\bar{L}) & =\frac{r}{\delta} .
\end{aligned}
$$

The value-matching condition (4) requires that the difference between the value of liquidity at $L^{*}$ and zero be exactly equal to the total cost of restoring liquidity to $L^{*}$ (from the zero level). Condition (5) requires that the value of liquidity at the target level $L^{*}$ be smaller than the value at barrier $\bar{L}$ exactly by the amount equal to the gain from reducing the liquidity level from $\bar{L}$ to $L^{*}$ (which equals the present value of future interest earned, $\frac{r\left(\bar{L}-L^{*}\right)}{\delta}$, net of the fixed transaction cost, $\left.M\right)$. Equations (6) and (7) are smooth-pasting conditions ensuring the optimality of the barriers. Consequently, at each of the barriers the marginal benefit of changing the liquidity level (represented by the first-order derivative of $F(L))$ is equal to the marginal cost of such a change $\left(\frac{r}{\delta}\right)$.

The value of liquidity, $F(L)$ can be represented as the following function of the model parameters as well as of barriers $\bar{L}$ and $L^{*}$ :

$$
F(L)=\bar{\Theta}(0, \bar{L} ; L)\left[\frac{\left(\bar{L}-L^{*}\right) r}{\delta}-M\right]-\underline{\Theta}(0, \bar{L} ; L)\left[\frac{L^{*} r}{\delta}+K\right]
$$

where $\bar{\Theta}(0, \bar{L} ; L)$ and $\underline{\Theta}(0, \bar{L} ; L)$, defined in Appendix B, are annuity-like factors representing the present value of a series of $€ 1$ payments received each time threshold 
$\bar{L}$ is hit or liquidity is exhausted, respectively. The first component of $(8)$ represents the present value of interest on (gross) long-term assets minus the associated transaction costs, whereas the second component equals the present value of interest paid on (gross) debt, including transaction costs. For a graphical illustration of the value of liquidity $F(L)$, see Figure 2.

[Insert Figure 2 about here]

The figure shows that for low liquidity levels $\left(L \in\left[0, L^{*}\right)\right)$ the marginal value of liquidity exceeds $\frac{r}{\delta}$. For high liquidity levels $\left(L \in\left(L^{*}, \bar{L}\right)\right)$ the marginal value of liquidity is less than $\frac{r}{\delta}$. At $L^{*}$ and $\bar{L}$ the marginal value of liquidity equals exactly $\frac{r}{\delta}$. For example, if the household's discount rate, $\delta$, equals the market discount rate, $r$, then the marginal value of $€ 1$ of liquidity equals 1 at $L^{*}$ and $\bar{L}$.

\section{Empirical methodology}

Households' incremental financing decisions depend on their current liquidity level in the interval $(0, \bar{L})$. For example, upon exhausting liquidity $(L=0)$ the marginal benefit of creating financial slack exceeds the marginal cost of external financing $\left(F^{\prime}(L)>\frac{r}{\delta}\right)$. In such a case, a household would increase its level of net debt by a strictly positive amount $K+L^{*}$, up to the point at which the marginal benefit and the marginal cost are equal. (The discrete jump in liquidity results from a strictly positive fixed cost $K$.) On the other hand, upon hitting the threshold $\bar{L}$, the liquidity level is reduced until the marginal benefit of holding liquidity is as high as the marginal benefit of reducing net debt $\left(F^{\prime}(L)<\frac{r}{\delta}\right.$ for $\left.L \in\left(L^{*}, \bar{L}\right)\right)$. As a result, the level of $L$ is reset from $\bar{L}$ to $L^{*}$.

Following the discussion in the previous section, household $i$ pursues the following financing policy: $i$ ) it increases net debt as soon as liquidity is exhausted so that the amount of liquidity is restored to a positive level $L^{*}$, ii) it reduces net debt when liquidity rises above the upper trigger, $\bar{L}$, which results in depleting liquidity to level $L^{*}$, and $\left.i i i\right)$ it takes no action when the level of liquidity is between 0 and $\bar{L}$.

In the remainder of the section we develop the empirical analysis based on the model of section 2 in three stages. First, we derive the functional form of the stationary distribution of the household liquidity level. Second, we run a regression model of the determinants of liquidity to estimate for each household the average level of liquidity. Finally, we use those estimated values to test whether incremental liquidity decisions of households are consistent with our model. 


\subsection{Application of the stochastic liquidity model}

As we are dealing with a large cross-section of households but with a very limited timeseries dimension, we are unable to estimate the model for each household separately. Therefore, we assume that all households pursue the same liquidity policy up to a proportionality constant. In other words, a household with an average level of liquidity equal to, say, €2,000 starts reducing net debt at the liquidity level twice as high (or, borrows twice as much upon exhausting liquidity) as a household with an average level of liquidity of $€ 1,000$. The average liquidity level $E\left[L_{i t}\right]$ is therefore used as the scaling parameter. In such a framework, one can think of the set of parameters $\left(\mu, K, M, L^{*}, \bar{L}\right)$ as being scaled for each observation by $E\left[L_{i t}\right]$ and $\sigma^{2}$ as being scaled by $\left(E\left[L_{i t}\right]\right)^{2}$ (The variance parameter $\sigma_{i t}^{2}$ is denominated in $€^{2}$.) For instance, the ratio of the upper liquidity threshold for household $i$ at time $t$, and household $j$ at time $s$ $\left(\bar{L}_{i t} / \bar{L}_{j s}\right)$, corresponds to the ratios of average liquidity levels, $E\left[L_{i t}\right] / E\left[L_{j s}\right]$.

Consequently, $\mu_{i t}, K_{i t}, M_{i t}, L_{i t}^{*}$ and $\bar{L}_{i t}$ are all denominated in currency units. For example, parameter $\mu_{i t}$ denotes the expected annual appreciation of the liquidity stock if neither borrowing nor debt repayment occurs. $K_{i t}$ and $M_{i t}$ denote the lump-sum costs of borrowing and debt repayment, respectively, while $L_{i t}^{*}$ and $\bar{L}_{i t}$ denote the currency-denominated liquidity levels associated with the optimal liquidity policy of household $i$ in year $t$. Parameters $\mu, K, M, L^{*}$ and $\bar{L}$ are therefore interpreted as proportions of the average household liquidity level (e.g., if $K_{i t}=€ 100$ and $E\left[L_{i t}\right]=$ $€ 1,000$, then $K=0.1$ ). Furthermore, the variance parameter of the liquidity process (1), $\sigma^{2}$, is interpreted as a fraction of the squared average household liquidity level. Discount rate $\delta$ and interest rate $r$ are the only parameters which are constant across households.

The scalability property is very desirable since it allows us to derive the distribution of the normalised liquidity, which is common for all the households. To do so, we define $l_{i t} \equiv L_{i t} / E\left[L_{i t}\right]$ as the normalised liquidity. As a consequence of the scalability assumption, all observations $l_{i t}$ are drawn from the same distribution, the shape of which can be inferred based on the entire sample of households. The derivation of the piece-wise exponential density function $\varphi(l)$ of normalised liquidity is presented in Appendix C (cf. Bertola and Caballero (1990) and Dixit (1993)). An example of such a distribution is illustrated in Figure 3.

[Insert Figure 3 about here]

What is directly relevant to our empirical test, is the relationship between $\bar{l}, l^{*}$ and 
the mean of the distribution 12 This relationship directly depends on the magnitudes of transaction costs associated with increases and reductions of net debt ( $K$ and $M$, respectively) as well as on such economic parameters as $\mu, r, \delta$ and $\sigma{ }^{13}$ Therefore, once the inference is made about the shape of the distribution, we are able to draw conclusions about the relative transaction costs consistent with the plausible values of remaining model parameters.

Consequently, the empirical part of our study has three main objectives. First, we test whether household's liquidity policy generally follows the policy described in section 2. Second, by allowing our model to detect discrete changes in the level of liquid assets, we draw inferences about the relative locations of $\bar{l}, l^{*}$ and the mean. Finally, based on the inferred shape of the distribution and plausible values of remaining economic parameters, we provide conclusions about the (perceived) magnitudes of the transaction costs associated with changes in the level of net debt.

\subsection{Estimation of the expected liquidity level}

Estimation of the average liquidity level for each observation is done using regression analysis. We calculate the predicted liquidity level for each household by regressing liquidity on a number of explanatory variables for the entire sample. ${ }^{14}$ This predicted value of liquidity is used as a scaling variable in the regression analysis in section 3.3.

If we were to interpret our model very narrowly, we would expect all the households to be identical up to the proportionality constant. Therefore, a single variable related to the wealth of a household, such as total assets, would be sufficient for determining the average liquidity level ${ }^{15}$ To avoid imposing such a restrictive framework, we assume that the households pursue identical (up to the proportionality constant) liquidity policies but otherwise are heterogenous. As a consequence, we are able to adopt a more general model of the average liquidity level.

The determinants of the average liquidity level considered in our study are partially inspired by the study of corporate cash holdings by Opler, Pinkowitz, Stulz, and Williamson (1999). Obviously, factors affecting households' demand for liquidity differ from those for firms. When deciding on the average level of cash holdings, families consider mainly transaction and precautionary motives. Informational asymmetries

\footnotetext{
${ }^{12} \bar{l}$ and $l^{*}$ denote the normalised values of $\bar{L}_{i t}$ and $L_{i t}^{*}$, respectively.

${ }^{13}$ Strictly speaking, the shape of the distribution depends on the ratios of $\frac{\mu}{\sigma^{2}}, \frac{\delta}{\sigma^{2}}$ and $\frac{r}{\delta}$.

${ }^{14}$ By doing so, we follow, among others, Opler, Pinkowitz, Stulz, and Williamson (1999) and RhodesKropf, Robinson, and Viswanathan (2005)

${ }^{15}$ Other household financial characteristics such as income or debt would have no additional explanatory power as they would constitute the same proportion of total assets for each household. Moreover, non-economic characteristics such as age or educations would play no role at all.
} 
are unlikely to influence households' demand for liquidity as creditors can relatively easily observe a household's characteristics. Furthermore, no separation of ownership and control arises, which makes predictions based on agency-theoretic models not relevant. Still, we rely on such determinants of liquid asset holdings known from corporate finance literature as the leverage ratio, size, and cash flow (income). In addition, we supplement the set of explanatory variables with additional household-specific characteristics, such as age and education.

Just as bigger firms have on average a higher demand for liquidity, wealthier households are likely to maintain higher cash amounts. However, as a proportion of total assets these amounts may be lower, as the economy of scale argument is valid for both the transaction and precautionary motives for holding liquidity. Also, household size may proxy for the risk of financial distress or cash-flow uncertainty, and less wealthy families are expected to hold proportionally more cash for precautionary motives. Indeed, Opler et al. (1999) document a negative relation between firm size and cash holdings as a proportion to total assets. This follows a prediction of the static tradeoff theory of firm financing, where economies of scale in liquid assets exist and expected bankruptcy costs are negatively related to firm size. Hence, size is expected to have a positive but concave relation with the cash value of liquid assets.

Net income, the cash flow measure for households, holds an ambiguous relation with liquidity. Like firms, households experiencing a positive cash-flow shock may be expected to accumulate liquidity for a given predetermined expenditure (consumption) and debt reduction plan. However, households may be more "debt" averse than firms. Also, debt conveys fewer benefits to households than to firms (e.g., in terms of tax shield benefits or agency cost reduction). Therefore, households may use any excess income that could otherwise increase liquidity holdings to repay debt, even above the normal repayment plan (cf. the income and substitution effect of cash flow shocks in Riddick and Whited (2009)).

The demand for corporate liquidity increases with leverage, as companies with big financial commitments have their access to new debt restricted and therefore need more liquidity for precautionary motives. Similarly, if a family has high levels of debt, access to new debt in troublesome periods may be extremely expensive, if not impossible. Consequently, a higher level of liquidity holdings would be expected for highly indebted households. However, the higher demand may not be reflected in higher observed liquidity levels, as these families may face liquidity constraints, due to tight debt repayment schedules. As a result, observed liquidity levels may be below what would be predicted by demand. Therefore, the sign of the relationship between the leverage ratio and average liquidity is ex ante ambiguous.

The other two determinants of household liquidity that we consider are age and 
education. The preferred level of liquid assets varies over the life cycle. People of different ages have different perceptions of the amount of liquidity they require to proceed with their daily economic activities, and the level of liquidity required as a "safety net". For example, pensioners and older people tend to be more cautious. Hence, these individuals are expected to keep higher amounts in liquid assets held for precautionary motives. Furthermore, most debt is paid off by later age, providing more scope for liquidity to build up. Therefore, a positive relation between age and liquidity is expected.

Education has a major influence on the way individuals develop their financial choices, and thus should be considered in an empirical test of the determinants of household liquidity. Higher educated individuals are typically subject to less risky financial situations, and lower income uncertainty. Considering this argument, education would have a negative expected relation with cash holdings. However, other factors may also play a role. Highly educated people may be more risk averse (or, financially aware), and face lower financing constraints. In such a case, they would be expected to build up liquidity to its optimal (higher) level ${ }^{16}$

Finally, we control for five other factors directly associated with households' assets and wealth. To take into account a potentially higher risk aversion of retired individuals, we use an additional dummy to represent those households that receive a pension. One of the major goals of most households is a house tenure. Hence, prior to purchasing a house, liquidity accumulation is likely to occur (so that a substantial initial down-payment on the home can be accumulated). Therefore, we include home ownership and mortgage debt as explanatory variables. To take into account the predictability (and expectation) of the income flow, we include two additional dummies for employment and self-employment.

The basic empirical model of the determinants of expected household liquidity is therefore as follows 17

$$
\begin{aligned}
E\left[L_{i t}\right]= & \hat{\gamma_{0}}+\hat{\gamma_{1}} S I Z E_{i t}+\hat{\gamma}_{2} I N C_{i t}+\hat{\gamma_{3}} L E V_{i t} \\
& +\hat{\gamma}_{4} A G E_{i t}+\hat{\gamma}_{5} E D U_{i t}
\end{aligned}
$$

where $E\left[L_{i t}\right]$ is the expected liquidity (defined below), $S I Z E_{i t}$ is the natural logarithm of total assets, $I N C_{i t}$ is the household's total net income, $L E V_{i t}$ is the ratio of total debt to total assets, $A G E_{i t}$ is the age of the eldest person in the household, and $E D U_{i t}$

\footnotetext{
${ }^{16}$ Tong (2010) analyses the relation between risk attitude and cash holdings using US firm data.

${ }^{17}$ The standard errors are adjusted for clustering at the household level to deal with multiple observations for the same household in different years. Since nearly $50 \%$ of households are observed only once, the fixed-effects/random-effects estimators are not a viable alternative (as their use would result in disregarding those observations).
} 
is a dummy variable equal to 1 for tertiary education, and 0 otherwise. Parameter estimates $\gamma_{i}, i \in\{0,1, \ldots, 5\}$, are obtained using an OLS regression specification. An extension of the basic model includes three additional dummy variables: PENSION - equal to 1 for pensioners, and 0 otherwise, $O W N E R_{i t}$ - equal to 1 for homeowners, and 0 otherwise, $M T G_{i t}$ - equal to 1 for mortgage holders, and 0 otherwise, EMPL $L_{i t}$ - equal to 1 for employed individuals, and 0 otherwise, and $S E L F_{i t}$ - equal to 1 for self-employed individuals, and 0 otherwise.

In the empirical specification we consider two different definitions of liquidity. The narrower measure of liquidity, $L_{i t}^{(0)}$, considers as liquid assets cash and checking accounts. The broader measure, $L_{i t}^{(1)}$, includes savings and deposit accounts in addition to components of $L_{i t}^{(0)} 18$

\subsection{A test of incremental financing decisions}

Our test of incremental financing decisions resembles to a large extent the test of the pecking order theory on corporations (Shyam-Sunder and Myers (1999), Frank and Goyal (2003)). For firms, the test aims to identify which of the two sources of external financing, debt and equity, is used in the first place. In a household finance application, such an approach would be impossible to implement since equity is never issued. Therefore, we aim to investigate the incremental financing decision by looking at whether households finance their needs using primarily short-term liquid assets and resort to long-term financial assets or borrowing if the former are exhausted.

First, define the deficit as $-\Delta W_{i t}$, that is, the negative change in net worth (resulting from a particular realization of transitory income). The balance sheet of a household can be expressed as $W_{i t}+B_{i t}=S_{i t}+L_{i t}$, where $B_{i t}, S_{i t}$, and $L_{i t}$ denote the levels of borrowing, long-term financial assets and liquidity, respectively. Changes in net worth, $-\Delta W_{i t}$, are observable via the balance sheet identity:

$$
\begin{aligned}
-\Delta W_{i t} & =\Delta B_{i t}-\Delta S_{i t}-\Delta L_{i t} \\
& \equiv \Delta D_{i t}-\Delta L_{i t},
\end{aligned}
$$

where $\Delta D_{i t}$ is the change in net debt. According to our model, the deficit arising in a given period is financed first with short-term liquid assets, $-\Delta L_{i t}$, and - as they become exhausted - with additional (net) debt, $\Delta D_{i t}$.

Therefore, we expect to observe the following piecewise-linear relationship between incremental net debt and the deficit 19

\footnotetext{
${ }^{18}$ For details of all the variables included in each liquidity definition, as well as descriptives for the sample, see Table 1.

${ }^{19}$ We do not assume any fixed costs of borrowing at this stage.
} 


$$
\Delta D_{i t}= \begin{cases}0 & -\Delta W_{i t}<L_{i, t-1} \\ -\Delta W_{i t}-L_{i, t-1} & -\Delta W_{i t} \geq L_{i, t-1}\end{cases}
$$

This is equivalent to

$$
-\Delta L_{i t}= \begin{cases}-\Delta W_{i t} & -\Delta W_{i t}<L_{i, t-1} \\ L_{i, t-1} & -\Delta W_{i t} \geq L_{i, t-1} .\end{cases}
$$

By observing that depleting short-term liquidity is preferred to increasing net debt, the following formulation is used in the first test of the stochastic liquidity model:

$$
-\Delta l_{i t}=\vartheta-\theta \Delta w_{i t}+\eta_{i t}
$$

where $\vartheta$ and $\theta$ are parameters to be estimated and $\eta_{i t}$ is the error term. Variables $-\Delta l_{i t}$ and $-\Delta w_{i t}$ are defined as $-\Delta L_{i t} / E\left[L_{i t}\right]$ and $-\Delta W_{i t} / E\left[L_{i t}\right]$, respectively, as the model is formulated in terms of normalised variables. The null hypothesis that the entire deficit is covered by depleting short-term liquid assets is equivalent to $\vartheta=0$ and $\theta=1$. In other words, model $(12)$ stipulates a euro-for-euro linear relationship between financing needs and the use of short-term financial assets (see Figure 4, Panel A). Obviously, such a formulation can be too restrictive as liquidity may eventually be exhausted and a household may have to resort to debt financing or, equivalently in our framework, to reducing the level of long-term financial assets. Consequently, (12) can be viewed as a test of the liquidity model for households having sufficiently high liquidity levels to cover any potential deficits.

One way of incorporating the possibility of exhausting liquidity is to allow $\theta$ to be lower than 1 under the null hypothesis (cf. the "weak form" interpretation of financing hierarchy in Shyam-Sunder and Myers (1999)). However, there are some shortcomings of such an approach (as pointed out first by Chirinko and Singha (2000)). A coefficient smaller than one may indicate not only partial debt financing after depleting internal cash but also financing of any deficit with some combination of liquid assets and changes in net debt.

In order to overcome these problems, we design an alternative test of incremental deficit financing decisions. The fact that we are testing the use of short-term liquid assets versus net debt puts us in a comfortable position of being able to observe whether short-term liquidity is exhausted or not (cf. panel B of Figure 4) ${ }^{20}$

\footnotetext{
${ }^{20}$ Our approach differs therefore substantially from the one adopted in corporate finance (as in Shyam-Sunder and Myers (1999) and Frank and Goyal (2003)). Corporate capital structure tests consider debt versus equity. Since debt capacity is not observable it is not possible to determine when firms have exhausted their capacity to borrow. In our test, which considers liquidity versus (net) debt financing, we can observe when a household's liquid assets have been exhausted.
} 
Consequently, our empirical formulation is of the following form ${ }^{21}$

$$
-\Delta l_{i t}-l_{i, t-1}=\vartheta+\theta \min \left\{-\Delta w_{i t}-l_{i, t-1}, 0\right\}+\eta_{i t}
$$

where $l_{i, t-1}$ is defined as $L_{i, t-1} / E\left[L_{i t}\right]$. In such a test, $\vartheta=0$ and $\theta=1$ would indicate that only short-term liquid assets are used to finance deficits not exceeding $l_{i, t-1}$, and a mix of liquidity (amounting to $l_{i, t-1}$ ) and net debt is used to finance deficits exceeding the existing level of short-term liquid assets, $l_{i, t-1}$. Consequently, such a result would support the one-sided case of the liquidity model with $K=0$ and $M \rightarrow \infty$ (i.e. no fixed cost of increasing net debt and no possibility of reducing net debt).

A more flexible test of the incremental financing decision, which reflects the effective debt requirement to finance larger deficits, is of the form:22

$$
-\Delta l_{i t}-l_{i, t-1}=\vartheta+\theta_{1}\left(-\Delta w_{i t}-l_{i, t-1}\right)+\theta_{2} \max \left\{-\Delta w_{i t}-l_{i, t-1}, 0\right\}+\eta_{i t} .
$$

The null hypothesis of the special case of the liquidity model with $K=0$ and $M \rightarrow \infty$, is supported for $\vartheta=0, \theta_{1}=1$ and $\theta_{2}=-1$. A value for $\theta_{2}=-1$ corresponds to the household increasing its net debt by $-\Delta w_{i t}-l_{i, t-1}$, which places liquidity back at the predicted level. Compared to model (13), model (14) allows for an extra degree of freedom as the slope of the relationship between the deficit and the change in liquid assets is not restricted to zero for levels of deficit exceeding $l_{i, t-1}$ (see Panel C).

Apart from following the developed framework to normalise variables with $E\left[L_{i t}\right]$, we have not made use of the results obtained in section 2. We need them for the full-fledged test of incremental financing decisions. In such a test, an upper barrier $\bar{l}$ at which households start reducing net debt is present. To accommodate this requirement, we use a range of candidate values for $\bar{l}$ in the following test:

$$
\begin{aligned}
-\Delta l_{i t}-l_{i, t-1}= & \vartheta+\theta_{0} \min \left\{-\Delta w_{i t}-l_{i, t-1}+\bar{l}, 0\right\}+\theta_{1}\left(-\Delta w_{i t}-l_{i, t-1}\right) \\
& +\theta_{2} \max \left\{-\Delta w_{i t}-l_{i, t-1}, 0\right\}+\eta_{i t} .
\end{aligned}
$$

The upper bound of the distribution of normalised short-term liquid assets, $\bar{l}$, is in itself a function of the parameters of this distribution, such as the drift rate, volatility or transaction costs. As $\bar{l}$ cannot be obtained analytically, we perform extensive simulations to determine its likely values for plausible parameter configurations. We

\footnotetext{
${ }^{21}$ The reason for shifting both the explained and the explanatory variable by $l_{i, t-1}$ results from the need for the functional form of the empirical model to be independent from the household characteristics $\left(l_{i, t-1}\right.$ in this case). This shift is exactly what differentiates our approach from existing contributions. To extend these other approaches in a similar fashion requires knowledge of debt capacity.

${ }^{22}$ This test does not prevent the coefficient of the deficit to be different from zero even for the incremental part of the deficit exceeding $l_{i, t-1}$.
} 
obtain that $\bar{l}$ in most cases falls into interval $(1.5,3.5)$. Therefore, we select $\bar{l}=2$ as our base case. In addition, $\bar{l}=2$ appears to be a good benchmark as it is consistent with a symmetric distribution of $l$. As an extension, we also perform a grid search for the best model fit for $\bar{l} \in[1,4]$ with a step size of 0.1 .

Under specification (15), a kink at $-\Delta w_{i t}=-\bar{l}+l_{i, t-1}$ is expected as a result of the fact that any liquidity above the amount $\bar{l}$ is used to reduce the level of debt. Therefore, for surpluses exceeding $\bar{l}-l_{i, t-1}$, the marginal effect of an additional euro of surplus should not have any effect on the level of short-term liquid assets as it will be used to reduce net debt (in other words, the slope of the graph in Panel D is expected to be zero to the left of $\left.-\bar{l}+l_{i, t-1}\right)$. Consequently, we expect that $\theta_{0}=-1$. Also, and as before, we expect $\vartheta=0, \theta_{1}=1$ and $\theta_{2}=-1$.

As a robustness check of (15), we perform an empirical test allowing for the slope of the regression function for negative values of the explanatory variable $-\Delta w_{i t}$ (which correspond to households facing a surplus) to differ from the slope over the remaining interval. The corresponding regression specification has the form

$$
\begin{aligned}
-\Delta l_{i t}-l_{i, t-1}= & \vartheta+\theta_{0} \min \left\{-\Delta w_{i t}, 0\right\}+\theta_{1}\left(-\Delta w_{i t}-l_{i, t-1}\right) \\
& +\theta_{2} \max \left\{-\Delta w_{i t}-l_{i, t-1}, 0\right\}+\eta_{i t},
\end{aligned}
$$

where we expect $\theta_{0} \in(-1,0)$. The advantage of using specification $(16)$ is that it does not require knowledge of the upper barrier of liquidity, $\bar{l}$, at which a household would invest in long-term financial assets (make a debt repayment). Its downside is that it is subject to the critique of Chirinko and Singha (2000) that a slope smaller (in absolute terms) than one does not have an unambiguous interpretation (cf. Panel E).

Finally, to test for the presence of a fixed cost of increasing $(K)$ and reducing net debt $(M)$, we allow for additional degrees of flexibility that capture the discontinuities of the explained variable (see Panel F):

$$
\begin{aligned}
-\Delta l_{i t}-l_{i, t-1}= & \vartheta+\theta_{0} \min \left\{-\Delta w_{i t}-l_{i, t-1}+\bar{l}, 0\right\}+\theta_{1}\left(-\Delta w_{i t}-l_{i, t-1}\right) \\
& +\theta_{2} \max \left\{-\Delta w_{i t}-l_{i, t-1}, 0\right\} \\
& +\kappa_{0} D_{0, i t}+\kappa_{1} D_{1, i t}+\eta_{i t} .
\end{aligned}
$$

$D_{0, i t}$ is a dummy variable that equals 1 if the surplus is sufficiently large to optimally trigger a reduction in net debt (i.e., $-\Delta w_{i t}<-\bar{l}+l_{i, t-1}$ ) and 0 otherwise. Analogously, $D_{1, i t}$ is a dummy variable that equals 1 if the deficit is large enough to trigger additional borrowing (i.e., $-\Delta w_{i t}>l_{i, t-1}$ ) and 0 otherwise. A positive value for $\kappa_{0}$ (i.e., $\kappa_{0}>0$ ) and a negative value for $\kappa_{1}$ (i.e., $\kappa_{1}<0$ ) would indicate positive lump-sum costs of debt reduction and borrowing, respectively. The expected absolute magnitudes of $\kappa_{0}$ and $\kappa_{1}$ equal the distance between the relevant resetting barrier and the target liquidity 
level $\left(\bar{l}-l^{*}\right.$ and $l^{*}$, respectively). In turn, distances $\bar{l}-l^{*}$ and $l^{*}$ are monotonic in the transaction cost parameters $M$ and $K$, respectively.

\section{Data}

The data set used to empirically test our model is based on the DNB Household Survey (DHS) carried out by CentERdata, a data collection unit of the Center for Economic Research at Tilburg University (the Netherlands). The rotating panel follows yearly over 2000 representative households in the Netherlands since 1993, and provides unique information about the financing, spending, labor and social decisions of individual households. The panel is constructed with the objective of reflecting the composition of the Dutch population. Bi-annual refreshment samples are drawn with the main objective of keeping the panel representative of the Dutch population. In the finance literature, the data from the DNB survey has been used, among others, by Guiso, Sapienza, and Zingales (2008).

The Netherlands is a particularly interesting country of study for household finance. The Dutch financial system is relatively well developed, and Dutch households exhibit a high level of financial sophistication and are sensitive to changes in the institutional setting and to financial incentives potentially produced in their economic environment (see Alessie, Hochguertel, and van Soest (2002)).

Since households are making decisions in an economic environment determined by some features that are specific to the Netherlands (for example, one of the lowest rates of home ownership in the EU, a tenant-friendly legal code or the proliferation of fixed rate mortgages) one has to be careful in extrapolating the results to other countries. However, considering that we are implementing an analysis of basic liquid assets, we believe that many of our results also apply to other countries in Western Europe, such as the United Kingdom.

Our data set corresponds to the period 1992-2007. All currency-denominated values are expressed in euro (using the official NLG/€ conversion rate of 2.20371). Observations considered are the ones in which all relevant parts of the questionnaire were answered by household members. Families answering all parts of the questionnaire in several years are considered as different observations. In our main regression studies, potential correlation of these is considered by calculating robust standard errors.

The size of the data set that we use in the study is considerably smaller than the total number of observations in the DNB survey (in excess of 30,000). This is mainly due to the requirement that several different sections of the questionnaire contain complete answers in two consecutive years (needed for calculating changes in liquidity related 
variables). Furthermore, we removed from the sample households with leverage (defined as the ratio of total debt to total assets) above 2. This leaves us with 9,957 observations that are used in regression (9) predicting the average liquidity level. Another restriction on the sample size follows from the fact that only households with a positive estimated average liquidity level (based on regression (9)) are considered in models (12)-(17), as variables in those models are scaled by the predicted average liquidity level. As a result, we lose another 469 observations. Finally, to mitigate the influence of extreme observations, the dataset was truncated. After ranking all households with respect to $-\Delta w_{i t}$, the top and bottom $1 \%$ of households (that is, 189 observations corresponding to top deficits or top surpluses of funds) were removed from the sample. The advantage of this procedure is the elimination of households observing abnormal and sporadic situations in the household economic life, which lead to huge deficits or surpluses. Examples of such events would be home acquisition or a large inheritance. The procedure also eliminates the effect on the results of those households for which the predicted liquidity level (the scaling variable) is very close to zero. The final sample used in regressions (12)-(17) consists therefore of 9,299 observations.

\subsection{Data on liquid assets}

The DHS survey presents detailed data on household asset holdings, with a very thorough categorization. Table 1 presents the main liquid asset categories, descriptives for average liquid asset holdings in our sample, each asset category as a proportion of total assets, and two definitions of liquidity used in the remainder of the paper. The average household in our sample holds an average of $€ 2,749$ in short-term financial assets: cash and checking accounts. Deposit books as well as savings accounts and plans, comprising medium-term less liquid financial assets, account for $6.2 \%$ of total household assets, and are on average $€ 10,502$. Both categories of financial assets add up to our broader definition of liquidity, which has an average total value of $€ 15,097$ and corresponds on average to $7.6 \%$ of total household assets. Finally, long-term illiquid financial assets, which primarily consist of investments in mutual funds, stocks and bonds, have an average value of $€ 12,212$ and represent $6.1 \%$ of total household assets.

[Insert Table 1 about here]

Also, for the 9,299 households considered in our liquid asset dynamics regressions, and using the measure of liquidity $L^{(1)}$, we observe that $45.3 \%$ of households experience a deficit of funds. Also, of these households in deficit, $45.4 \%$ hold enough liquid assets to repay the deficit. For households with a surplus of funds, $12.8 \%$ have a total liquid assets value above twice the estimated average liquidity level. 


\section{Results}

This section presents the results of the estimation of the average liquidity level $E\left[L_{i t}\right]$ required for the testing of our proposed model (and implemented as in equation (9)), and the tests of incremental financing decisions proposed in equations $(12)-(17)$. Results are shown for the two definitions of liquid assets: the narrower definition, $L_{i t}^{(0)}$, considering only cash and checking accounts; and the broader definition, $L_{i t}^{(1)}$, considering the above plus deposit and savings accounts. In implementing regressions (12)-17) all variables are normalised by scaling the original values by the estimated average liquidity level $E\left[L_{i t}\right]$. In the base case, models (15) and (17) are estimated using $\bar{l}=2$ as the upper boundary of the liquidity distribution. An extension based on other levels of the upper barrier is also presented. We conclude the section with an analysis of the characteristics of those households for which the fit of our theoretical model is much worse.

\subsection{Determinants of the average liquidity level}

Table 2 presents the OLS regression results of the determinants of household liquidity $\left(L_{i t}^{(0)}\right.$ and $\left.L_{i t}^{(1)}\right)$. Model 1 presents the results of the basic regression in (96), which considers leverage, net income, household size, age and education as the explanatory variables. Model 2 further explores the cross-sectional variation in the sample by additionally including as determinants of liquidity such dummy variables as pensions, home ownership, mortgage presence, employment and self-employment. The estimated coefficients are mainly in line with our predictions.

[Insert Table 2 about here]

Household size, proxied by the natural logarithm of total assets, has a positive and highly significant relation with liquidity. The results are as predicted, since households with higher gross assets are expected to hold higher amounts of liquidity ${ }^{23}$ The coefficient of net income also exhibits a positive sign, and is significant. Results indicate that high income households finance their activities internally, repay due debt with remaining funds, and accumulate liquidity afterwards. Finally, leverage has a negative effect on the average liquidity level, which is a indication of financing constraints faced by highly indebted households.

\footnotetext{
${ }^{23}$ If the ratio of liquidity to total assets - a relative measure - is the dependent variable, then the estimated household size coefficient is, however, negative. This confirms the economies of scale argument described in section 3.2 .
} 
The prediction that households adopt higher liquidity levels as they move through the life cycle is confirmed, with positive and significant coefficients observed for the age factor. However, the age factor loses some magnitude in Model 2, possibly due to the fact that some older people are pensioners, and age is capturing this effect in Model 1. Also, although the education coefficient is negative, which could lead to the conclusion that more educated households appear to hold less liquid assets, the results are statistically significant only for liquidity definition $L_{i t}^{(0)}$.

Regarding the additional variables present in Model 2, pensioners have significantly higher amounts of liquidity. It is likely that higher risk aversion reduces them to hold more liquidity for precautionary motives. Homeowner households, however, appear to hold significantly less liquidity than non-homeowner households. This fact confirms the process of liquid asset accumulation by renters, potentially with the ultimate objective of a downpayment on a house. Mortgaged homeowner households seem to hold higher levels of liquid assets than unmortgaged owner households. However, the effect is not statistically significant. The employment dummy variable is positive and highly significant for $L_{i t}^{(1)}$ but not for $L_{i t}^{(0)}$. This indicates that employment status does not affect the shortest-term liquid asset holdings. Finally, self-employment is a significant positive determinant of $L_{i t}^{(0)}$, but not of $L_{i t}^{(1)}$.

The regression results explaining $L_{i t}^{(0)}$ and $L_{i t}^{(1)}$ allow us not only to understand the main factors driving liquid asset holding, but also to create an estimate of the average liquidity level $E\left[L_{i t}\right]$ required to scale variables in 12 - 17). In the remainder of the paper, estimates of $E\left[L_{i t}\right]$ are based on the results of Model 2.

\subsection{Incremental financing decisions}

The regression results for the incremental financing decisions by households are shown in Tables 3 and 4, with Table 3 reporting results based on $L_{i t}^{(0)}$ and Table 4 those based on $L_{i t}^{(1)}$. The regression specifications become more flexible (in terms of degrees of freedom) when moving to the right of each table and the results of these more flexible models generally follow more closely the predictions of the theoretical model.

[Insert Tables 3 and 4 about here]

Regression results of the basic test of the preference of internal liquidity to external financing as proposed in (12), and similar to the empirical test of the pecking order theory proposed by Shyam-Sunder and Myers (1999), give a slope coefficient of 0.009 for $L_{i t}^{(0)}$ and and 0.098 for $L_{i t}^{(1)}$ and deviate from the predicted value of one for the coefficient of $-\Delta w_{i t}$ (using the $5 \%$ confidence intervals). In both cases, the intercept is close to the 
predicted value of zero (the difference is not significant at the $5 \%$ level). These results appear to indicate only a partial external (debt) financing of the deficit of funds by households. Several critiques of this basic test applied to corporate capital structure (see Chirinko and Singha (2000)) also hold for our framework. Although suitable for households with a very high level of liquid assets, this test leads to ambiguous interpretations for the coefficients of the deficit variable $\left(-\Delta w_{i t}\right)$ that are lower than 1.

In general, we expect a lower coefficient for the narrower definition of short-term liquidity $\left(L_{i t}^{(0)}\right)$ than for the broader definition of short-term and medium-term liquidity $\left(L_{i t}^{(1)}\right)$. This is due to the fact that larger deficits usually have to be financed by some combination of liquidity and net debt. For any size of the deficit, the probability of financing it entirely with short-term liquid assets (which is equivalent to the slope coefficient being equal to 1) is lower than the probability of financing it with a combination of short-term and medium-term assets 24

Equation (13) provides an alternative test of household behaviour in the presence of a funds deficit. It explicitly takes into account the fact that net debt needs to be increased once short-term liquid assets are exhausted. Since the available amount of short-term assets is observable we know exactly when short-term liquidity is exhausted. We obtain a slope coefficient of 0.017 for $L_{i t}^{(0)}$ and of 0.224 for $L_{i t}^{(1)}$, which is in both cases significantly different from 1 at the $5 \%$ level. The results of regression 13 suggest once more that the financing of the arising deficits is being made through a combination of liquid funds and an increase in net debt. The results suggest that net debt is increased before existing liquid assets are fully exhausted. As expected, a greater share of the deficit is funded by liquidity if we consider the definition $L_{i t}^{(1)}$, compared to $L_{i t}^{(0)}$ where households rely to a larger extent on net debt. Also, an accumulation of liquid assets independent of the level of the deficit and its partial financing, appears to exist for both liquidity definitions, as the estimated coefficient $\vartheta$ is negative and significant.

A more flexible test of incremental financing decisions is conducted using (14). Results obtained are of a very similar magnitude to the ones just discussed. The results confirm a partial reduction of liquidity by households in deficit prior to new debt being issued as $\theta_{1}$ and $\theta_{2}$ exhibit some distance from the theoretically predicted values of 1 and -1 , respectively (they are equal to 0.017 and -0.018 for $L_{i t}^{(0)}$ and 0.228 and -0.249 for $L_{i t}^{(1)}$, respectively). As before, results are much closer to the predicted magnitudes if considering $L_{i t}^{(1)}$, for which around a quarter of the available liquidity is

\footnotetext{
${ }^{24}$ As a robustness check, we have re-estimated equations 12 -17 with observations corresponding to the top and bottom 5, 10 and $25 \%$ of the normalised deficit level removed from the sample. As expected, regression coefficients of the basic model specifications move closer to 1 if these extreme observations are removed.
} 
exhausted before the level of net debt is increased.

In model (15), we introduce an upper barrier $\bar{l}$ at which households start repaying debt (or investing in long-term assets) by using excess liquidity. Our candidate value is 2 (see section 3.3). Empirical results partially confirm our theoretical predictions. Namely, if $L_{i t}^{(1)}$ is considered, the estimated value of $\theta_{1}$ is 0.735 (predicted $\theta_{1}=1$ ), whereas the estimate of $\theta_{2}$ equals -0.806 (predicted $\theta_{2}=-1$ ). The estimated parameter values indicate that household fund deficits are covered mostly with the available liquidity stock. In households a significant reduction in the level of net debt is observed - the estimated value of $\theta_{0}$ is -0.739 (predicted $\theta_{0}=-1$ ). Some accumulation of liquid assets beyond the defined upper threshold may reflect situations that the households commonly face, such as an accumulation of assets for home purchase, or the lack of alternative financial investments (e.g., the accumulation of liquid assets by the elderly after mortgage repayment). A partial reduction in net debt is also observed for the tighter liquidity definition $L_{i t}^{(0)}$, as $\theta_{0}=-0.356$. Results for model 16 , implemented as a robustness check to the more data demanding model (15), support the aforementioned conclusions.

The results obtained so far are broadly confirmed by the (more complex) setting of (17), where discrete changes in short-term liquid assets resulting from debt repayment and borrowing are considered. For specification (17), the estimation results support (for both liquidity definitions) the hypothesis that there discrete positive changes in short-term liquid assets when net debt increases. This result is consistent with a strictly positive lump-sum cost associated with increasing net debt. For $L_{i t}^{(1)}, \kappa_{1}=-0.356$, whereas for $L_{i t}^{(0)}, \kappa_{1}=-0.224$ (both coefficients are significant at the $1 \%$ level). The existence of discrete reductions in short-term liquid assets associated with lowering the level of net debt would be confirmed by a strictly positive estimate for the coefficient $\kappa_{0}$. However, for neither of the definitions of liquidity $\kappa_{0}$ is positive, which indicates that households do not associate reductions in net debt with lump-sum cost and, as a result, do not pursue them in a discrete fashion 25 To summarise, the results of (17) indicate that the discrete change $l^{*}$ at the lower liquidity threshold is greater than the change $\left(\bar{l}-l^{*}\right)$ at the upper threshold. In other words, $l^{*} \in\left(\frac{\bar{l}}{2}, \bar{l}\right)$.

\footnotetext{
${ }^{25}$ We assume that the incremental financing structure decisions do not entail any "round trips". In other words, the annual deficit is implicitly interpreted as the supremum of all deficits between $t-1$ and $t-1+\tau$, where $\tau \in[0,1]$. However, this is just an approximation. In general an additional debt issue occurring when $-\Delta w_{i t}<l_{i, t-1}$ (i.e., when the deficit can apparently be financed using internal liquidity) does not automatically contradict our model. In fact, it may have happened that during the course of the year the household ran into a deficit bigger than $l_{i, t-1}$ (which triggered a debt issue) and only later it bounced back. The round trips potentially contribute to the estimated regression coefficients in models (12)-17) to be smaller (in absolute terms) than 1. Furthermore, without the round trips, the sum of absolute values of $\kappa_{0}$ and $\kappa_{1}$ would equal $\left(\bar{l}-l^{*}\right)+l^{*}=\bar{l}$.
} 
Table 5 presents sensitivity results of regressions (15) and (17) with respect to the upper bound of household liquidity, $\bar{l}$, considering definition $L_{i t}^{(1)}$. As mentioned before, a grid search is performed to identify the best model fit for $\bar{l}$ ranging from 1 to 4 (with a step size of 0.1 ). The best fit (the highest $R^{2}$ ) is obtained with $\bar{l}=2.6$ for specification 15) and with $\bar{l}=3.1$ for 17 ). (In both cases $R^{2}$ is an inverted U-shaped function of $\bar{l}$.) For $\bar{l}=3.1$, both the sign and significance of $\kappa_{0}$ improve. Still, only a partial adjustment of liquidity to reduction of net debt is observed.

[Insert Table 5 about here]

Having determined $\bar{l}$ associated with the best model fit and concluding that $l^{*} \in$ $\left(\frac{\bar{l}}{2}, \bar{l}\right)$, we are now in position to infer the magnitude of the transaction costs $K$ and $M$, associated with increases and reductions in net debt, respectively. To do so, we use the system of equations (4)-(7), and use the equation for the distribution mean to link $l^{*}$ and $\bar{l}$ with other model parameters. To eliminate the remaining degrees of freedom, we adopt the estimate of income volatility of Dutch households of 0.197 obtained by DiazSerrano (2005) and assume that $r=\delta=0.0426$ Solving the model for $\bar{l} \in\{2.6,3.1\}$ and $l^{*} \in\left(\frac{\bar{l}}{2}, \bar{l}\right)$ indicates that the (perceived) lump-sum cost of increasing net debt, $K$, varies from 0.10 to 0.21 (as a fraction of the average liquidity level) and is generally much higher than the cost of reducing net debt, $M$, which ranges from 0.01 to 0.11 . The estimated costs $K$ and $M$ decrease with the assumed level of $l^{*}$ and $K(M)$ decreases (increases) with $\bar{l}$. Furthermore, both costs increase with the assumed level of $r$ and decrease with $\sigma$.

To summarise the main part of the empirical analysis, our evidence supports to a large extent the theoretical prediction that the presence of a financing deficit leads in the first instance to the depletion of the stock of (internal) liquidity and only then is followed by an increase in the level of net debt. Still, even with the most flexible model specification, the relevant adjustment coefficients are smaller (in absolute values) than 1 , which indicates that the financing hierarchy is followed only imperfectly. Throughout Tables 3-5 we report confidence intervals of the estimated coefficients. The results of the empirical analysis only partially support the hypothesis that the excess funds over the (theoretically predicted) upper liquidity threshold are used to reduce the level of net

\footnotetext{
${ }^{26}$ To obtain an estimate of the actual volatility of liquidity process (1), we assume that there are no transitory changes in consumption (see Appendix A) and that any shocks to income level fully translate into shocks to the (unconstrained) liquidity level. Subsequently we scale income volatility by the ratio of average liquidity to average income (0.56) to obtain the (standardised) estimate of $\sigma$. Obviously, if transitory changes in consumption absorb a strictly positive fraction of shocks to income, the actual $\sigma$ will be lower and the estimates of the transaction costs consistent with it - higher.
} 
debt. Furthermore, we find evidence of a (perceived) significant lump-sum transaction cost associated with increases in the level of net debt and of a substantially lower cost associated with its reductions.

\subsection{Analysis of households adopting sub-optimal financing de- cisions}

Previously we found that our financing hierarchy is only partially supported by the data. This suggests that some households may be behaving sub-optimally. In this section we try to identify households that behave sub-optimally and their characteristics. We subsequently examine in what way their liquidity policy deviates from the one predicted by our model.

As highlighted in the introduction, overdrafts constitute a very expensive source of financing and they are therefore likely to be symptomatic of suboptimal financing decisions. We therefore first analyse whether, and to what extent, households in our sample rely on overdrafts. Subsequently we identify the characteristics of households that use overdrafts using a probit and tobit model with, respectively, the presence (a binary variable) and the monetary level of overdrafts as dependent variable. Finally, we examine whether those household characteristics and the mere presence of overdrafts help explaining household liquidity policy.27

We start off by analysing the occurrence and the level of overdrafts across households. As overdrafts constitute an expensive form of financing, which is likely inconsistent with the minimisation of financing costs, the analysis of overdrafts is useful in two ways. Firstly, the empirical model of incremental financing decisions can be extended to explicitly take into account the fact that some households use overdrafts. If the presence of an overdraft is interpreted as irrational behaviour, such an extension would allow us to test whether incremental financing decisions of households that use overdrafts are further away from those predicted by our model. Secondly, identifying the determinants of overdrafts is useful in selecting explanatory variables that are potentially associated with less-than-rational financial decision making. We subsequently test whether those variables indeed affect the incremental financing decisions.

For our initial sample of 9,957 observations, an overdraft is reported for $7.27 \%$ of household-years. $4.41 \%$ of households report an overdraft every year and $87.38 \%$ never resort to this source of financing. A simple analysis of variance (ANOVA) confirms that the occurrence of an overdraft differs significantly between households. In other words, household identity (household fixed effect) is a significant determinant of an overdraft occurrence $(F=3.11$ rejects the hypothesis that household fixed effects are

\footnotetext{
${ }^{27}$ We thank the anonymous referee for suggesting the analysis of overdrafts.
} 
not jointly significant at the $1 \%$ level). If we replace an overdraft occurrence with its value and do an ANOVA on the overdraft levels, then there is no systematic difference across households $(F=1.03$ implies that the fixed effects are not significant at the $10 \%$ level). We conclude that the variation of overdraft levels cannot be explained by the household fixed effects due to a high within variation of the overdraft levels ${ }^{28}$

As overdrafts do not occur randomly across households, we investigate household characteristics that explain the presence and the level of overdrafts. We predict that financially more sophisticated households (cf. Campbell (2006)) will tend to use overdrafts less often and to a lesser extent. Consequently, the probability and the magnitude of an overdraft is expected to be negatively related to income $(I N C)$, wealth $(S I Z E)$ and education $(E D U)$, and positively related to leverage $(L E V)$, age $(A G E)$, unemployment (UNEMPL) and social benefits (BENEFIT). We do not form expectations regarding the direction of the effect of being self-employed $(S E L F)$, pensioner status (PENSION), the number of kids (KIDS), being a homeowner $(O W N E R)$ or having an outstanding mortgage contract $(M T G)$. The signs of the estimated coefficients of a probit model largely confirm our predictions. We find (see Table 6, column 3 ) that the probability of a household having an overdraft is positively related to $L E V$, $S E L F$ - but to a smaller magnitude than UNEMPL - as well as to BENEFIT and $K I D S$. In turn, the probability of observing an overdraft is negatively influenced by $S I Z E$. All the results are significant at the $1 \%$ level with an exception of $S I Z E(5 \%)$ and BENEFIT (10\% level). Upon analysing the marginal effects, it can be concluded that unemployment $(U N E M P L)$ is the most highly economically significant determinant of the probability of resorting to an overdraft facility. To complete the analysis, we identify the determinants of the magnitude of overdrafts across households by estimating a tobit model. The expected magnitude of overdrafts is explained essentially by the same variables as its probability, except that $S I Z E$ and BENEFIT lose their statistical significance and $A G E$ becomes statistically significant (see Table 6, column 5).

Since the use of overdraft accounts may be interpreted as a symptom of a suboptimal financing policy, we hypothesize that households using overdrafts are also more likely to deviate from the optimal policy predicted by our model. Consequently, we augment the empirical specification (17) by including interaction terms that capture the effect of overdraft use. Such an approach is equivalent to splitting the total sample into two subsamples - with and without overdrafts - and allows us to test the significance of the differences in key model coefficients and to compare discrete changes related to increases/reductions in net debt. By comparing the incremental

\footnotetext{
${ }^{28}$ This finding can therefore be interpreted as the average level of an overdraft being the same (i.e., the actual level being drawn from the same distribution) across households.
} 
policies of households with and without overdrafts (see Table 7, column 2) we show that the former are more likely to finance their deficit with debt even if short-term liquidity is not fully exhausted (the coefficient of $\left(-\Delta w_{i t}-l_{i, t-1}\right)$ is reduced by 0.375 ). Moreover, households with overdrafts appear to borrow too little (and, as a result, too frequently) once their short-term financial assets are actually fully exhausted (a positive coefficient of $D_{1} * O V E R D R A F T$, where $O V E R D R A F T$ is a dummy equal to 1 if a household uses an overdraft facility and 0 otherwise, indicates a reduced magnitude of the lump-sum borrowing). Those results imply that the behaviour of households using overdrafts indeed differs from other households' and from the behaviour predicted by our theoretical model.

Finally, we analyse whether the household characteristics that determine the presence and level of overdrafts also affect a household's incremental financing policy. In particular, we analyse the effect on liquidity policy of dummy variables linked to income, total assets, leverage, age, benefit and unemployment. For all continuous variables of interest, the dummies are defined according to whether the relevant explanatory variable is above or below its median. Therefore, we define INCL and SIZEL, as dummy variables equal to 1 if $I N C$ and $S I Z E$, respectively, are below their median and to 0 otherwise. Analogously, we define $L E V H$ and $A G E H$ as dummy variables equal to 1 if $L E V$ and $A G E$, respectively, are above their median and to 0 otherwise ${ }^{29}$

We use again model (17) augmented with a range of interaction terms to capture the effect of the variable of interest. The results of our tests support to a large extent the hypothesis that the factors affecting the probability and level of overdrafts also affect the incremental financing policy (see Table 7, columns 3-8). Borrowing before fully exhausting liquidity is particularly common for households with high leverage - the coefficient of $\left(-\Delta w_{i t}-l_{i, t-1}\right) * L E V H_{i t}$ equals -0.052 (cf. column 5). Once short-term liquid assets are exhausted, borrowing too little and too frequently occurs predominantly among households with low income, low assets and those who are unemployed the coefficient of $D_{1} * X 30$ for $X \in\{I N C L, S I Z E L, U N E M P L\}$ equals 0.106, 0.145, and 0.292 , respectively, which means that for these 3 categories the amount being borrowed upon exhausting liquidity is smaller. Finally, elderly households and those receiving social benefits appear not to adequately reduce their levels of net debt after accumulating excess liquidity - the coefficient of $D_{0} * X$ equals -0.512 for $X=A G E H$ and -0.603 for $X=B E N E F I T$.

[Insert Tables 6 and 7 about here]

\footnotetext{
${ }^{29}$ Education and the number of kids are not significant determinants of the incremental financing decisions, so we do not report them.

${ }^{30}$ Recall that $D_{1}=1$ indicates that the deficit exceeds the amount of short-term liquid assets.
} 


\section{Conclusions}

We develop and test a theoretical model of household liquidity inspired by the stochastic inventory management literature. According to our theoretical model, households do not optimally increase net debt before short-term liquid assets are exhausted. If the liquidity level hits zero, households take on enough debt to place liquid assets at a positive level. Furthermore, the model considers the possibility of a surplus of funds, and predicts that net debt is optimally reduced above a certain upper liquidity threshold.

We test our model predictions using a panel data set of Dutch households. We estimate the upper liquidity threshold at which a reduction in net debt occurs - by partial repayment or investment in long-term financial assets. Five key liquidity determinants, required for the implementation of our incremental financing decisions model, are considered (we further extend the model for additional five determinants). Household size and income are shown to affect positively the average level of household liquidity. Household leverage appears to affect negatively the average level of liquid asset holdings. Although more educated households take on less liquidity, the relation is statistically significant only for the narrower definition of liquidity that does not include medium-term liquid assets. The significance of the age factor shows an increasing importance of the precautionary motive for holding liquidity while moving through the life cycle. Older people may also have a stronger preference towards cash to execute financial transactions.

Concerning the incremental financing model, our empirical results for households facing a deficit of funds are largely consistent with the theoretical predictions, and are in line with a financing policy where households use the various financing options according to a strict order of preference. Households use debt financing or deplete the stock of long-term financial assets only after their liquidity is substantially reduced. However, our prediction of debt repayment (or investment in long-term assets) for the levels of liquidity above the derived upper threshold is only partially supported in our sample, which indicates that the perceived benefits of reducing net debt may vary widely across households. Furthermore, we find evidence of significant fixed transaction costs associated with increases in the level of net debt, whereas decreases in the level of net debt do not appear to entail costs of such a magnitude.

The finding that the financing hierarchy is only partially supported suggests that some households may not be behaving optimally. First, elderly households and those receiving benefits appear not to reduce adequately their level of net debt after accumulating excess liquidity. Second, some households have a significant amount of short-term liquidity while having costly overdrafts. In fact, households having overdrafts appear to borrow small amounts on a frequent basis, which indicates they ignore 
the fixed costs (fees) associated with this sub-optimal liquidity policy. In our data sample households with overdrafts tend to have few assets, high leverage and they are more likely to be unemployed.

Our results have implications for regulators, lenders and policy makers. First, our result that the implied transaction costs associated with increasing net debt are much higher than those associated with reducing net debt suggests that policy measures aimed at reducing frictions associated with the former may not only be necessary but also more effective. Second, our finding that a small minority of poor and vulnerable households rely too much and too frequently on the most costly forms of financing (such as overdrafts) implies that there is clearly a need for providing those people with more financial education, advice and protection. Some countries (like the US) have in the wake of the recent crisis introduced legislation to protect consumers and adopted bills that restrict overdraft services. Third, the fact that some households engage in costly overdraft borrowing while holding substantial amounts of liquidity may be a symptom of the cash management problem described in the introduction. If this sub-optimal behaviour is indeed a result of the increased complexity (such as managing multiple accounts) and volume of a household's financial transactions then there seems to be a need for a banking service that links a customer's various accounts more efficiently together. For example, a service that automatically transfers available funds from a savings account to an account that risks being overdrawn could save customers a lot of money in overdraft fees. Finally, our results show that some households (especially the elderly) accumulate excessive amounts of short-term liquidity. We can only speculate about the reasons for this. It might be because these households are more risk-averse and therefore have a higher precautionary need for liquidity. They might prefer cash transactions and attach a higher implied value to cash. Some might not be aware (or not be bothered) that they are losing money by not investing in long-term financial assets with a higher return. Others might have a very short horizon or perceive the risk of liquidity shortage in the economy to be unreasonably high. If some of these conjectures are true then boosting consumer confidence as well as maintaining trust in the financial system may be important policy goals, particularly during recessions. The excess liquidity in the hands of some households also suggests a potential source of funds governments could tap into. In the wake of the credit crunch and sovereign debt crisis some governments are considering to borrow more extensively from their own citizens (and less for foreign investors) and to make government debt more attractive by making it exempt from income tax, for example.

The absence of strong results concerning debt repayment and the transfer of liquid assets to long-term assets are aspects certainly worth exploring in future research. Different types of households may have different incentives to proceed with debt re- 
payment or to engage in long-term investments, and hence may adopt very different liquidity policies. For example, pensioners having no debt may exhibit inertia in shifting their investments, or households saving for home acquisition may not be keen on investments involving high withdrawal penalties. 


\section{A Derivation of the liquidity dynamics}

The liquidity model of Section 2 is formally rationalized as follows. Assume that a household has an infinite horizon (cf. Deaton (1993), Wang (2006)) and that its cumulative income process follows an arithmetic Brownian motion

$$
\mathrm{d} Y_{t}=\alpha \mathrm{d} t+\sigma \mathrm{d} z_{t}
$$

where $\alpha$ is the expected value of the instantaneous income flow and $\sigma$ is its standard deviation. Consequently, $\sigma \mathrm{d} z_{t}$ is interpreted as the difference between the expected and realized income over interval $\mathrm{d} t$. Such a model specification corresponds to income being distributed normally in a discrete time setting.

In a perfect capital market, that is, with borrowing rate $r$ equal to the lending rate and no transaction costs, a household's wealth $W_{t}$ would have the following dynamics

$$
\mathrm{d} W_{t}=\mathrm{d} Y_{t}+r W_{t} \mathrm{~d} t-c_{t} \mathrm{~d} t=\left(\alpha+r W_{t}-c_{t}\right) \mathrm{d} t+\sigma \mathrm{d} z_{t}
$$

where $c_{t}$ is the level of the household's instantaneous consumption. Equation A.2 is interpreted as follows: the change in wealth over interval $\mathrm{d} t$ equals the sum of the realized income stream and the capital gain on the existing wealth reduced by the household's consumption.

In a situation, in which borrowing (and, potentially, saving) is associated with transaction costs, the household finds it optimal to maintain a liquidity balance. In such a case, the dynamics of wealth is given by an equation similar to A.2 but which also takes into account the the transaction costs as well as the forgone interest on any liquidity balance. Before deriving such an equation, let us first observe that the balance sheet of the household can be written as $W_{t}+B_{t}=S_{t}+L_{t}$, where $B_{t}, S_{t}$, and $L_{t}$ denote the levels of borrowing, savings and liquidity, respectively. The instantaneous change in the level of wealth can therefore be written as

$$
\mathrm{d} W_{t}=\left[\alpha+r\left(S_{t}-B_{t}\right)-K \xi_{K}-M \xi_{M}-c_{t}\right] \mathrm{d} t+\sigma \mathrm{d} z_{t},
$$

where $\xi_{i}, i \in\{K, M\}$ denotes an indicator function that has the value of 1 if the fixed transaction cost $i$ is incurred in interval $\mathrm{d} t$ and zero otherwise. Equation (A.3) simply states that the change in wealth over interval $\mathrm{d} t$ equals the sum of the realized instantaneous income stream and the interest on net savings reduced by any transaction costs and the household's consumption. Given that the balance sheet identity also holds for changes in the levels

$$
\mathrm{d} W_{t}+\mathrm{d} B_{t}=\mathrm{d} S_{t}+\mathrm{d} L_{t}
$$


the dynamics of stochastic process for liquidity is obtained by adding $\mathrm{d} B_{t}-\mathrm{d} S_{t}$ to the RHS of A.3. Since

$$
\begin{aligned}
\mathrm{d} S_{t} & =\left(r S_{t}+\Delta_{S} \xi_{M}\right) \mathrm{d} t, \text { and } \\
\mathrm{d} B_{t} & =\left(r B_{t}+\Delta_{B} \xi_{K}\right) \mathrm{d} t,
\end{aligned}
$$

where $\Delta_{S}\left(\Delta_{B}\right)$ is the lumpy saving (borrowing) made upon hitting the savings threshold (exhausting liquidity), household liquidity $L_{t}$ is governed by

$$
\mathrm{d} L_{t}=\left[\alpha+\left(\Delta_{B}-K\right) \xi_{K}-\left(\Delta_{S}+M\right) \xi_{M}-c_{t}\right] \mathrm{d} t+\sigma \mathrm{d} z_{t},
$$

At this point, we need to impose a simplifying assumption that results in consumption being constant over time. Namely, we assume that the household's consumption level is only a function of time and not of the state variable and that the household's discount rate $\delta$ is consistent with a constant consumption path under such a scenario ${ }^{31}$ In such a case, liquidity follows the controlled arithmetic Brownian motion:

$$
\begin{aligned}
\mathrm{d} L_{t} & =\left[\alpha+\left(\Delta_{B}-K\right) \xi_{K}-\left(\Delta_{S}+M\right) \xi_{M}-c\right] \mathrm{d} t+\sigma \mathrm{d} z_{t} \\
& \equiv\left[\mu+\left(\Delta_{B}-K\right) \xi_{K}-\left(\Delta_{S}+M\right) \xi_{M}\right] \mathrm{d} t+\sigma \mathrm{d} z_{t} .
\end{aligned}
$$

Equation (A.6) is therefore equivalent to (1) inside the control boundaries, that is, when $\xi_{K}=\xi_{M}=032$

Finally, to obtain $\mu$, we determine the optimal consumption level, such that the value of the household's wealth and liquidity (that takes into accounts income and consumption dynamics) is zero:

$$
0=W_{0}+G\left(L_{0} ; \mu=\alpha-c\right)
$$

with

$$
G(L) \equiv F(L ; \delta=r)
$$

being the value of the liquidity (see (8)) with household discount rate $\delta$ replaced with market rate $r$.

\footnotetext{
${ }^{31}$ If no such assumptions were made, one would need typically to maximise the integral of the discounted instantaneous utilities of consumption subject to the wealth constraint. Such a maximisation would be equivalent to solving the stochastic optimal control problem that would yield the optimal instantaneous level of consumption as a function of two state variables $W_{t}$ and $L_{t}$. As the resulting Bellman equation would have a form of a partial differential equation, an analytical solution would be unlikely.

${ }^{32}$ In fact, consumption can be allowed to partially reflect shocks to the income process $Y_{t}$. In such a case the stochastic component of the process governing the liquidity dynamics equals $\rho \sigma \mathrm{d} z_{t}$, with $\rho \in(0,1)$.
} 


\section{B Stochastic discount factors and annuity formulae}

First, we observe that the present value of $€ 1$ received upon hitting an upper boundary $\bar{L}$ before exhausting liquidity for a current level of liquidity equal to $L$ is given by (cf. Dixit (1993)):

$$
\bar{\Lambda}(\bar{L}, 0 ; L) \equiv E\left[e^{-r T_{\bar{L}}} \mathbf{1}_{\left\{T_{\bar{L}}<T_{0}\right\}} \mid L\right]=e^{(\bar{L}-L)\left(\frac{\mu}{\sigma^{2}}+a\right)} \frac{e^{2 a L}-1}{e^{2 a \bar{L}}-1},
$$

where $T_{y}$ is the stopping time at realization $y$ of process (1) and

$$
a \equiv \sqrt{\left(\frac{\mu}{\sigma^{2}}\right)^{2}+\frac{2 r}{\sigma^{2}}}
$$

Similarly, we define the present value of $€ 1$ received upon when liquidity is exhausted before $\bar{L}$ is hit as

$$
\underline{\Lambda}(\bar{L}, 0 ; L) \equiv E\left[e^{-r T_{0}} \mathbf{1}_{\left\{T_{\bar{L}}>T_{0}\right\}} \mid L\right]=e^{-L\left(\frac{\mu}{\sigma^{2}}+a\right)} \frac{e^{2 a(L-\bar{L})}-1}{e^{-2 a \bar{L}}-1} .
$$

Now, we can write (for simplicity, we drop the parameters of $\bar{\Lambda}($.$) and \underline{\Lambda}($.$) )$

$$
F(L)=\bar{\Lambda}(L)\left[\frac{\left(\bar{L}-L^{*}\right) r}{\delta}-M\right]-\underline{\Lambda}(L)\left[\frac{L^{*} r}{\delta}+K\right]+[\bar{\Lambda}(L)+\underline{\Lambda}(L)] F\left(L^{*}\right),
$$

where $F\left(L^{*}\right)$ is simply obtained by substituting $L^{*}$ for $L$ in $($ B.4 $)$. Consequently, $F(L)$ can be expressed as

$$
\begin{aligned}
F(L) & =\bar{\Lambda}(L)\left[\frac{\left(\bar{L}-L^{*}\right) r}{\delta}-M\right]-\underline{\Lambda}(L)\left[\frac{L^{*} r}{\delta}+K\right] \\
& +[\bar{\Lambda}(L)+\underline{\Lambda}(L)] \frac{\bar{\Lambda}\left(L^{*}\right)\left[\frac{\left(\bar{L}-L^{*}\right) r}{\delta}-M\right]-\underline{\Lambda}\left(L^{*}\right)\left[\frac{L^{*} r}{\delta}+M\right]}{1-\bar{\Lambda}\left(L^{*}\right)-\underline{\Lambda}\left(L^{*}\right)},
\end{aligned}
$$

which is equivalent to (8) with

$$
\begin{aligned}
\bar{\Theta}(0, \bar{L} ; L) & \equiv \frac{\bar{\Lambda}(L)\left[1-\underline{\Lambda}\left(L^{*}\right)\right]+\bar{\Lambda}\left(L^{*}\right) \underline{\Lambda}(L)}{1-\bar{\Lambda}\left(L^{*}\right)-\underline{\Lambda}\left(L^{*}\right)}, \text { and } \\
\underline{\Theta}(0, \bar{L} ; L) & \equiv \frac{\underline{\Lambda}(L)\left[1-\bar{\Lambda}\left(L^{*}\right)\right]+\bar{\Lambda}(L) \underline{\Lambda}\left(L^{*}\right)}{1-\bar{\Lambda}\left(L^{*}\right)-\underline{\Lambda}\left(L^{*}\right)} .
\end{aligned}
$$

\section{Stationary distribution}

Below, we present the derivation of the density function of normalised liquidity, $\varphi(l)$, for the general case, that is with non-zero drift rate and positive transaction costs. Using 
the discrete approximation of the process (1), the steady-state distribution should satisfy (see Dixit (1993))

$$
\varphi(l)=\varphi(l-\Delta l) p+\varphi(l+\Delta l)(1-p),
$$

where

$$
p=\frac{1}{2}\left(1+\frac{\mu \sqrt{\Delta t}}{\sigma}\right),
$$

with $\Delta l=\sigma \sqrt{\Delta t}$. By using Taylor expansion of C.1 and setting $\Delta t \rightarrow 0$, one obtains

$$
\frac{\sigma^{2}}{2} \varphi^{\prime \prime}(l)=\mu \varphi(l)
$$

The general solution is follows:

$$
\begin{aligned}
\varphi(l) & =A l+B \text { for } \mu=0, \\
& =A e^{\frac{2 \mu l}{\sigma^{2}}}+B \text { otherwise. }
\end{aligned}
$$

The coefficients of the general solution differ across different intervals of the domain of the controlled process $l$ (in this case, there are two intervals, $\left[0, l^{*}\right)$ and $\left[l^{*}, \bar{l}\right]$ ), such that (for $\mu \neq 0$; for $\mu=0$ solution is obtained analogously)

$$
\begin{aligned}
\varphi(l) & =A_{1} e^{\frac{2 \mu l}{\sigma^{2}}}+B_{1} \quad \text { for } \quad l \in\left[0, l^{*}\right), \\
& =A_{2} e^{\frac{2 \mu l}{\sigma^{2}}}+B_{2} \quad \text { for } \quad l \in\left[l^{*}, \bar{l}\right] .
\end{aligned}
$$

First, as resetting is applied at barriers, $\varphi(0)=\varphi(\bar{l})=0$. Second, the density function is continuous at $l^{*}$. Finally, it has to integrate over its domain to 13 The resulting constants $A_{1}, A_{2}, B_{1}$, and $B_{2}$ are given by

$$
\begin{aligned}
& A_{1}=\left[\frac{e^{\frac{2 \mu l^{*}}{\sigma^{2}}}-1}{e^{\frac{2 \mu \bar{l}}{\sigma^{2}}}-e^{\frac{2 \mu l^{*}}{\sigma^{2}}}} e^{\frac{2 \mu \bar{l}}{\sigma^{2}}}\left(\bar{l}-l^{*}\right)-l^{*}\right]^{-1}, \\
& A_{2}=-\left[e^{\frac{2 \mu \bar{l}}{\sigma^{2}}}\left(\bar{l}-l^{*}\right)-\frac{e^{\frac{2 \mu \bar{l}}{\sigma^{2}}}-e^{\frac{2 \mu l^{*}}{\sigma^{2}}}}{e^{\frac{2 \mu l^{*}}{\sigma^{2}}}-1} l^{*}\right]^{-1} \text {, } \\
& B_{1}=-A_{1} \text {, } \\
& B_{2}=-A_{2} e^{\frac{2 \mu \bar{l}}{\sigma^{2}}} .
\end{aligned}
$$

The mean of the distribution, $E[l]$, is determined by integrating $l \varphi(l)$ over its domain.

\footnotetext{
${ }^{33}$ If $K(M)$ is zero, $\varphi(0)(\varphi(\bar{l}))$ is strictly positive and $l^{*}=0\left(l^{*}=\bar{l}\right)$. Therefore, there is only one function specification to be determined, so two unknown constants are calculated using the two remaining conditions, i.e., that $\varphi(\bar{l})=0(\varphi(0)=0)$ and $\varphi(l)$ has to integrate over its domain to 1 .
} 


\section{References}

Agarwal, S., S. Chomsisengphet, C. Liu, and N. S. Souleles (2005): "Do consumers choose the right credit contracts?," University of Pennsylvania, Working paper.

Alessie, R., S. Hochguertel, and A. van Soest (2002): "Household Portfolios in the Netherlands," in Household Portfolios, ed. by L. Guiso, M. Haliassos, and T. Jappelli. MIT Press.

Bar-Ilan, A. (1990): "Overdrafts and the Demand for Money," American Economic Review, 80(5), 1201-1216.

Bates, T. W., K. M. Kahle, and R. M. Stulz (2009): "Why Do U.S. Firms Hold So Much More Cash Than They Used To?," Journal of Finance, 64, 1985-2022.

Baumol, W. J. (1952): "The Transactions Demand for Cash: An Inventory Theoretic Approach," Quarterly Journal of Economics, 66, 545-556.

Bertola, G., and R. Caballero (1990): "Kinked Adjustment Costs and Aggregate Dynamics," in NBER Macroeconomics Annual 1990, ed. by O. J. Blanchard, and S. Fischer. MIT Press.

Bolton, P., and H. Rosenthal (2005): Credit Markets for the Poor. Russell Sage Foundation, New York.

Campbell, J. Y. (2006): "Household Finance," Journal of Finance, 61(4), 15531604, Presidential Adress to the American Finance Association.

Chirinko, R., And A. R. Singha (2000): "Testing Static Tradeoff Against Pecking Order Models of Capital Structure: a critical comment," Journal of Financial Economics, 58, 417-425.

Deaton, A. (1993): Understanding Consumption. Oxford University Press.

Diaz-Serrano, L. (2005): "Income Volatility and Residential Mortgage Delinquency across the EU," Journal of Housing Economics, 14, 153-177.

Dittmar, A., And J. Mahrt-Smith (2007): "Corporate governance and the value of cash holdings," Journal of Financial Economics, 83(3), 599-634.

Dixit, A. K. (1993): The Art of Smooth Pasting, vol. 55 of Fundamentals of Pure and Applied Economics. Harwood Academic Publishers. 
Eisfeldt, A. L. (2007): "Smoothing with liquid and illiquid assets," Journal of Monetary Economics, 54(6), 1572-1586.

Frank, M. Z., And V. K. Goyal (2003): "Testing The Pecking Order Theory of Capital Structure," Journal of Financial Economics, 67, 217-248.

Guiso, L., M. Haliassos, and T. Jappelli (2002): Household Portfolios. MIT Press.

Guiso, L., P. Sapienza, And L. Zingales (2008): "Trusting the Stock Market," Journal of Finance, 63, 2557-2600.

Harrison, J. M., T. Sellke, and A. J. Taylor (1983): "Impulse Control of Brownian Motion," Mathematics of Operations Research, 8(3), 454-466.

Harrison, J. M., and M. I. TAKsar (1983): "Instantaneous Control of Brownian Motion," Mathematics of Operations Research, 8(3), 439-453.

Harrison, M. J. (1985): Brownian Motion and Stochastic Flow Systems. John Wiley \& Sons.

Keynes, J. M. (1936): The General Theory of Employment, Interest and Money. Harcourt Brace, New York.

Kim, C.-S., D. C. Mauer, and A. E. Sherman (1998): "The Determinants of Corporate Liquidity: Theory and Evidence," Journal of Financial and Quantitative Analysis, 33(3), 335-359.

Meleis, S., And H. IsRael (2010): "To Solve the Checking Problem, Solve the Household Cash Management Problem," American Banker, 175(77), 9.

Miller, M. H., And D. OrR (1966): "A Model of The Demand for Money by Firms," Quarterly Journal of Economics, 80, 413-435.

Opler, T., L. Pinkowitz, R. Stulz, and R. Williamson (1999): "The Determinants and Implications of Corporate Cash Holdings," Journal of Financial Economics, 52(1), 3-46.

Rhodes-Kropf, M., D. R. Robinson, and S. Viswanathan (2005): "Valuation Waves and Merger Activity: The Empirical Evidence," Journal of Financial Economics, 77, 561-603.

Riddick, L. A., And T. M. Whited (2009): "The Corporate Propensity to Save," Journal of Finance, 64(4), 1729-1766. 
Santomero, A. M. (1974): "A Model of the Demand for Money by Households," Journal of Finance, 29, 89-102.

Shyam-Sunder, L., And S. C. Myers (1999): "Testing Static Tradeoff Against Pecking Order Models of Capital Structure," Journal of Financial Economics, 51, 219-244.

Stango, V., And J. Zinman (2009): "What Do Consumers Really Pay on Their Checking and Credit Card Accounts? Explicit, Implicit, and Avoidable Costs," American Economic Review: Papers and Proceedings, 99(2), 424-429.

ToBin, J. (1956): "The Interest Elasticity of the Transactions Demand for Cash," Review of Economics and Statistics, 38, 241-247.

Tong, Z. (2010): "CEO Risk Incentives and Corporate Cash Holdings," Journal of Business Finance \& Accounting, 37(9-10), 1248-1280.

WANG, N. (2006): "Generalizing the permanent-income hypothesis: Revisiting Friedman's conjecture on consumption," Journal of Monetary Economics, 53(4), 737-752.

Whalen, E. (1965): "A Cross Section Study of Business Demand for Cash," Journal of Finance, 20, 1-19.

Wirth, A. (1984): "A Note on a Cash Management Model Allowing for Overdrafts," Journal of Business Finance \& Accounting, 11(4), 557-561.

Zinman, J. (2007): "Household Borrowing High and Lending Low Under NoArbitrage," Dartmouth College, Working paper. 
Figure 1: Liquidity Management Policy

The figure presents the representation of the optimal liquidity management policy. Barrier $L^{*}$ corresponds to the target liquidity level. Barrier $\bar{L}$ (zero) corresponds to the liquidity level that triggers a reduction (an increase) in net debt.

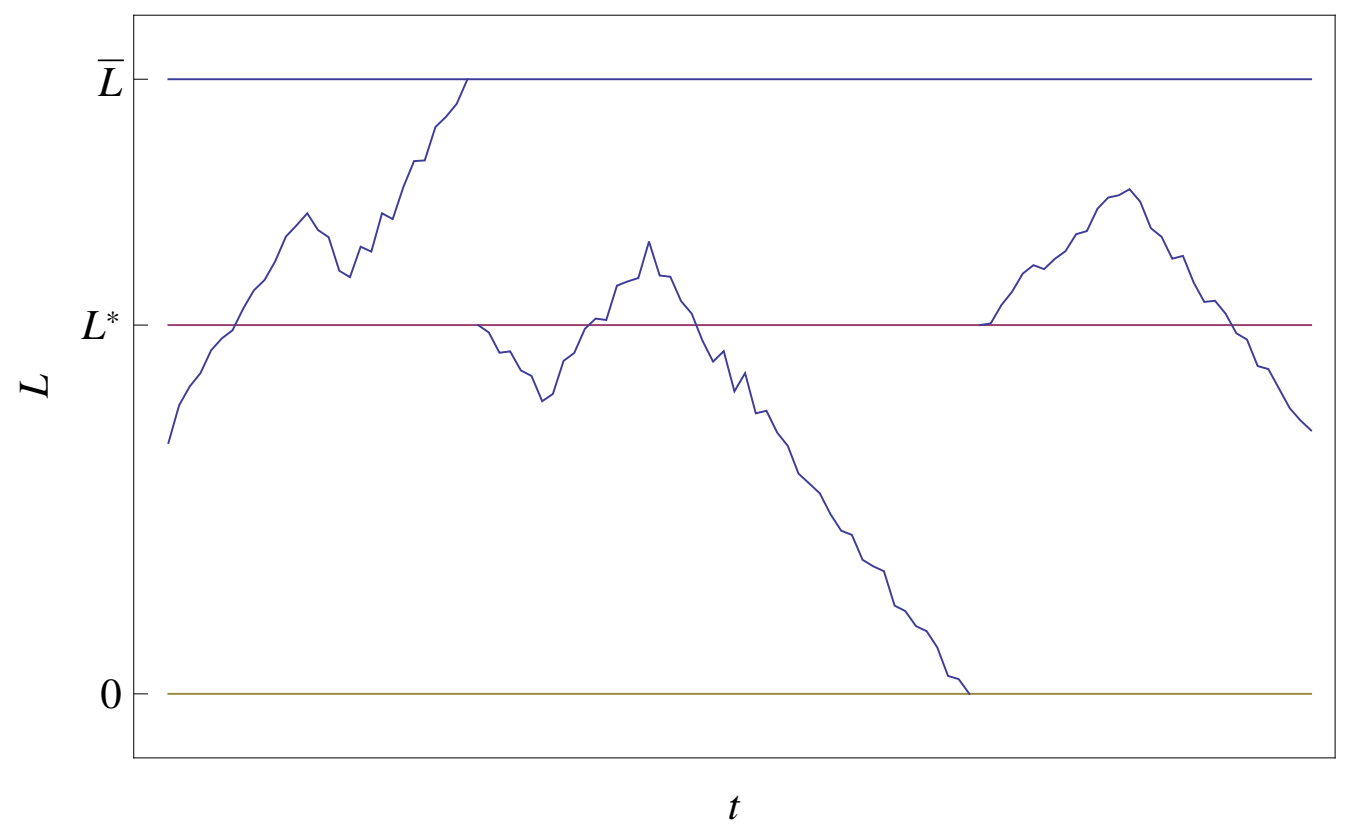




\section{Figure 2: The Value of Household Liquidity}

The figure presents the value of household liquidity, $F(L)$, for the following set of parameters: $K=0.15, M=0.05$, $r=0.05, \delta=0.05, \mu=0.04$, and $\sigma=0.1$. Barrier $L^{*}$ corresponds to the target liquidity level. Barrier $\bar{L}$ corresponds to the liquidity level that triggers a reduction in net debt.

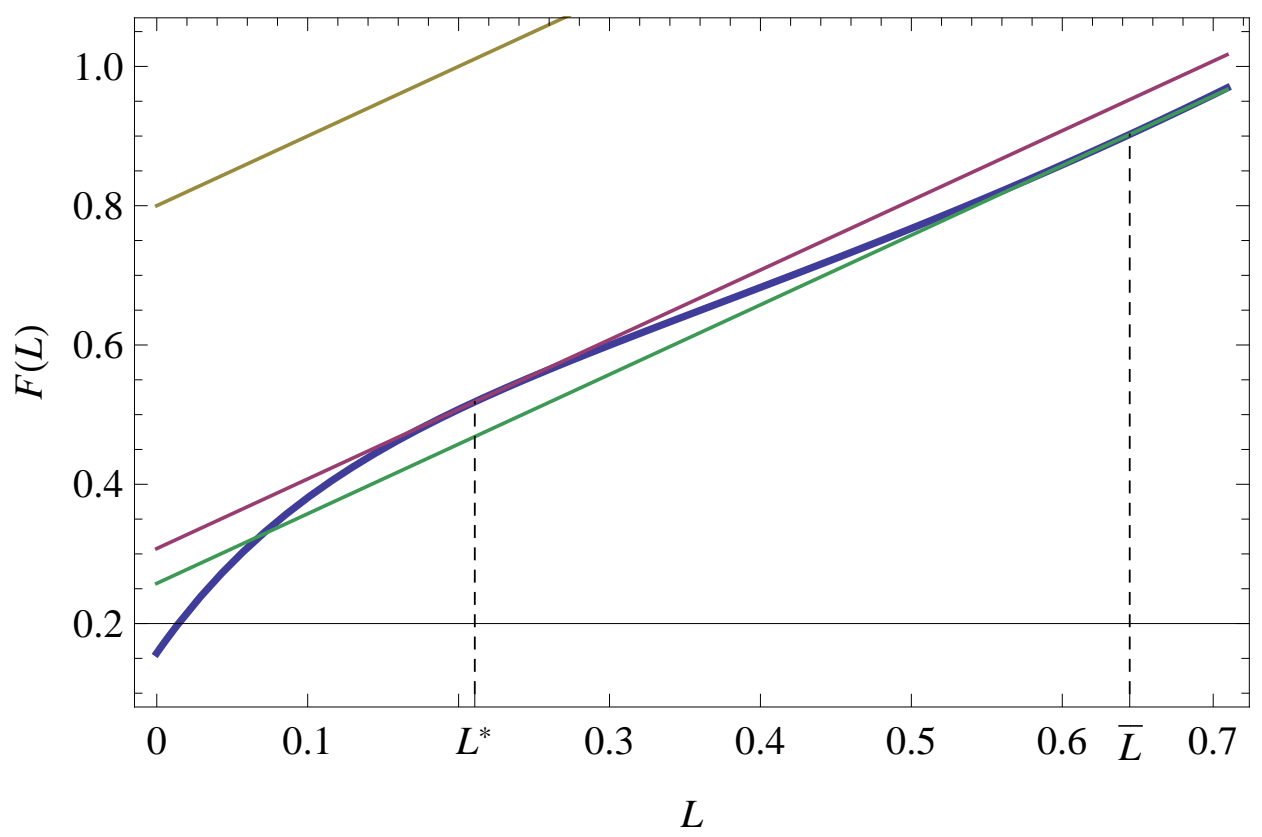


Figure 3: Stationary Distribution of Household Liquidity

The figure presents a stationary distribution of household normalised liquidity, $\varphi(l)$, for the following set of parameters: $r=0.05, \delta=0.04, \sigma=0.1 a, K=0.15 a, M=0.05 a, \mu=0.04 a$. The mean value, $E[l]=1$, of the distribution is represented with a dot. Parameter $a=2.95$ is used for normalisation to ensure that the mean of the distribution is 1 .

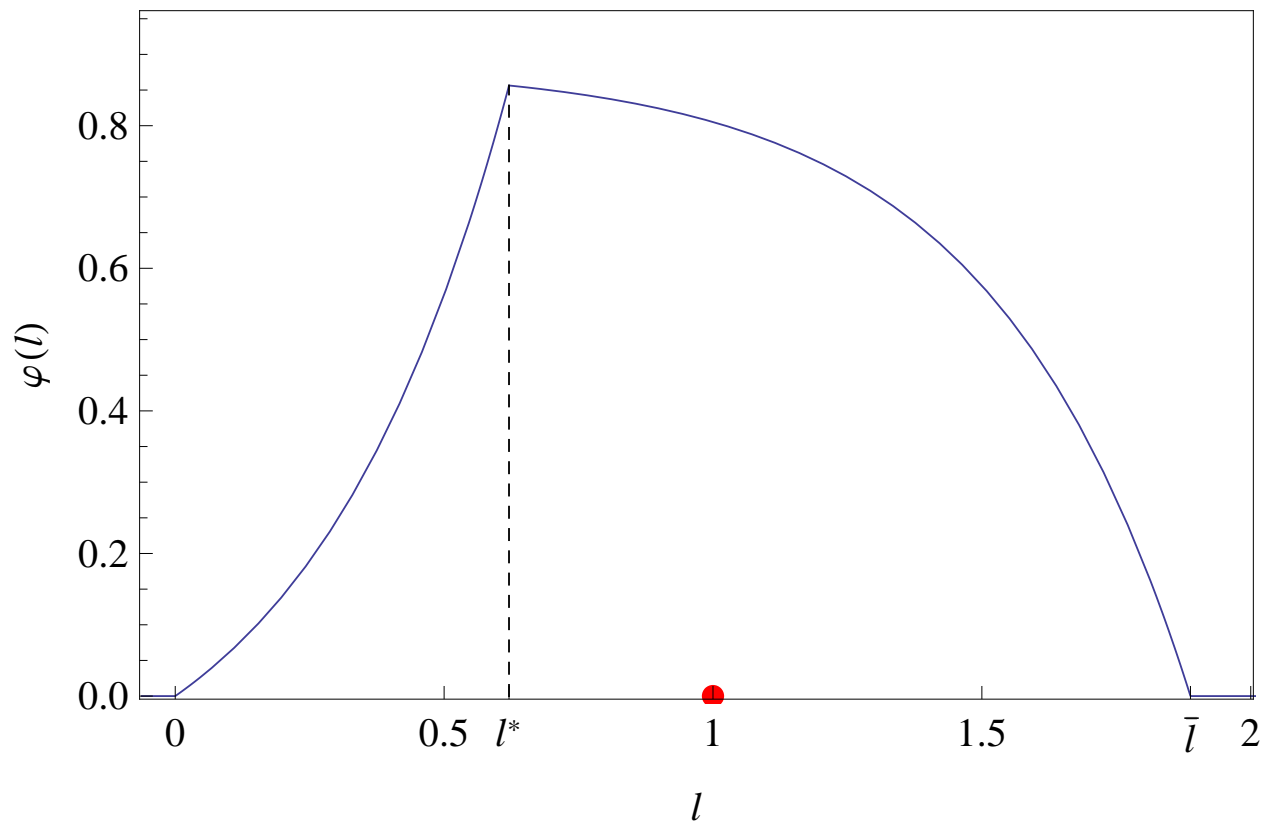




\section{Figure 4: Graphical Representation of Predicted Incremental Financing Decisions}

The figure presents the hypothesized coefficients of the incremental financing decisions models 12 - 17] (Panels A-F, respectively). The horizontal axis represents the deficit of funds $(-\Delta w)$ and the vertical axis represents the reduction of short-term liquid assets $(-\Delta l)$. Consequently, the top-right quadrant of each panel represents a situation in which a household faces the deficit of funds and depletes its short-term assets and the bottom-left quadrant corresponds to the surplus of funds. Discontinuous changes in $-\Delta l$ in panel $\mathrm{F}$ correspond to the resetting of the level of liquid assets to the target, $l^{*}$, associated with a reduction (the left-hand side of the graph) and an increase (the right-hand side) of net debt.

(A)

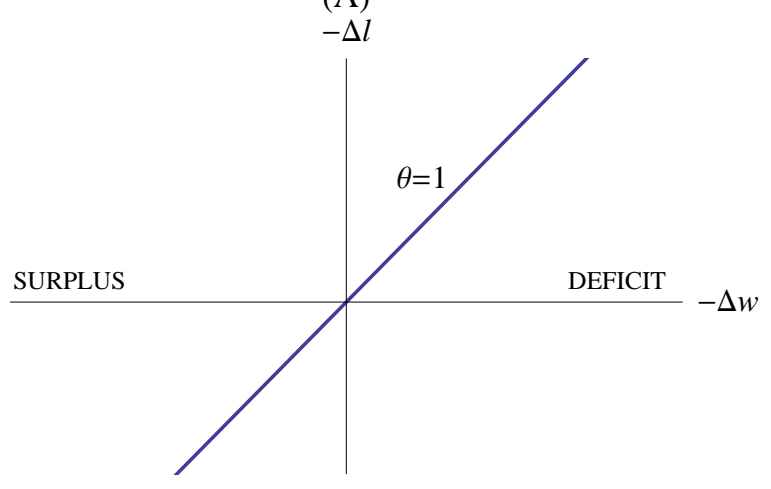

(C)

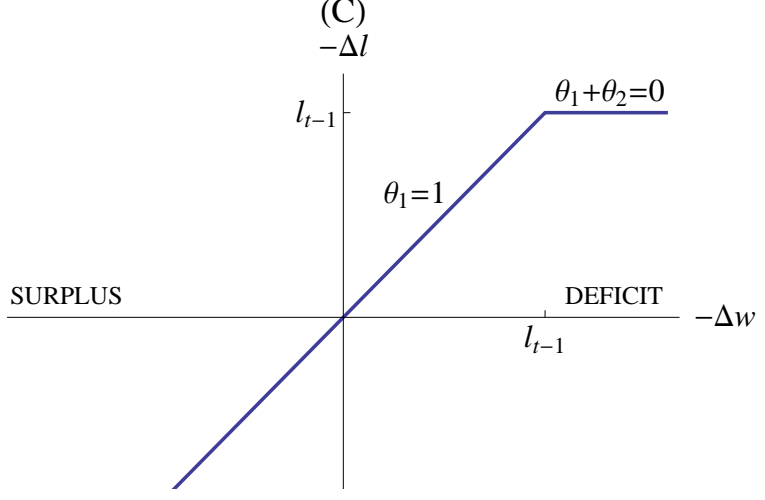

(E)

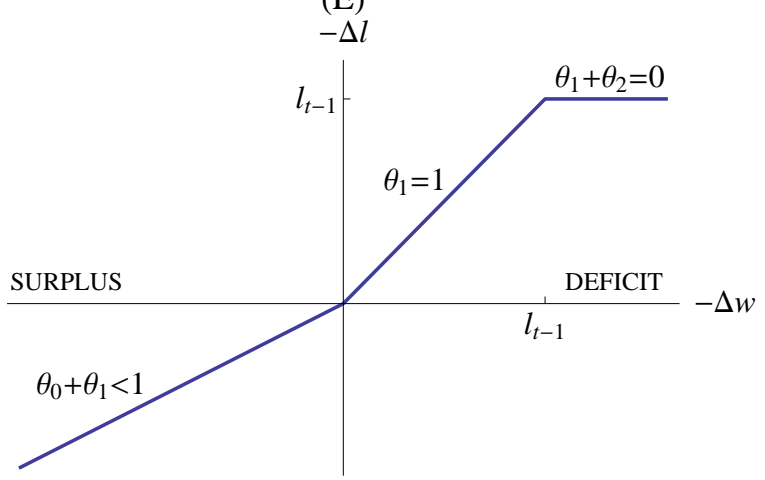

(B)

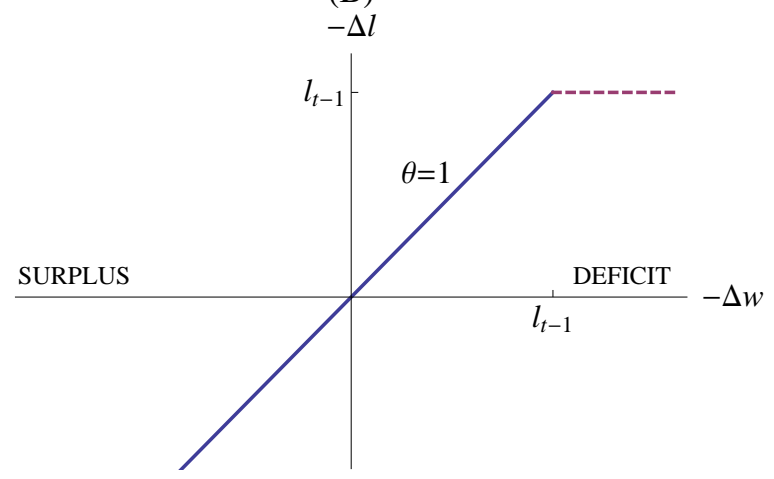

(D)

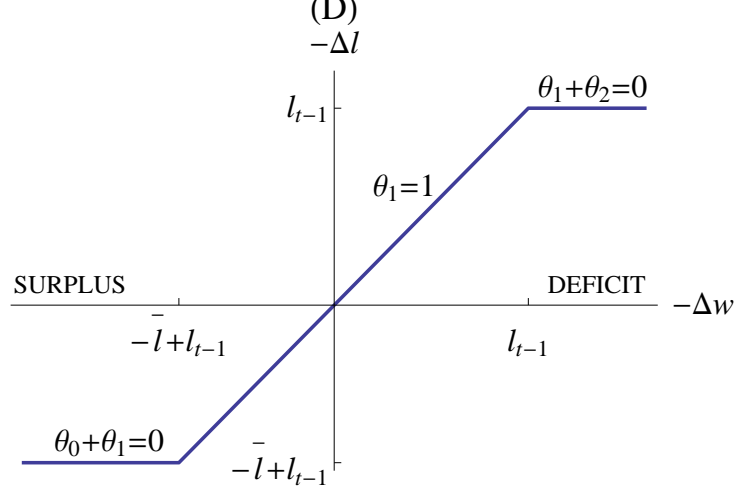

(F)

$-\Delta l$

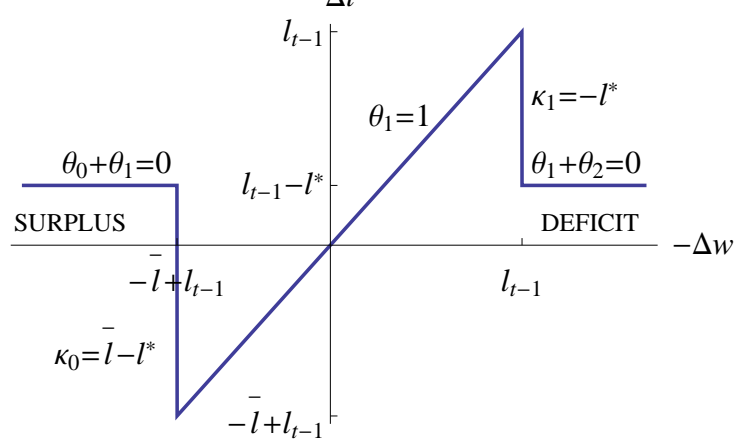


Table 1: Summary of Average Household Liquid Assets

The table presents liquid assets descriptives for the 9,957 Dutch households sample. The values presented are in euros. Also, the total values and proportions of the asset categories to liquidity variable $L_{i t}^{(1)}$ (cash and deposit accounts plus savings) and to total assets are presented.

$$
€ \quad \% L_{i t}^{(1)} \quad \% \text { Assets }
$$

Cash and Checking Accounts, $L_{i t}^{(0)} \quad 2,748.9 \quad 18.2 \% \quad 1.4 \%$

\section{Savings}

- Deposit Books

$\begin{array}{lll}1,846.2 & 12.2 \% & 0.9 \% \\ 8,888.6 & 58.9 \% & 4.5 \% \\ 1,613.7 & 10.7 \% & 0.8 \%\end{array}$

Total $L_{i t}^{(1)}$

$15,097.4 \quad 100.0 \% \quad 7.6 \%$

Other Financial Assets

$12,212.1$

$6.1 \%$

Total Debt

$56,962.4$

$28.5 \%$

Net Debt

$44,750.3$

$22.4 \%$

Total Assets 
Table 2: Determinants of Household Expected Liquidity

The dependent variable is household liquid assets, measured as cash and deposit accounts $\left(L_{i t}^{(0)}\right)$ and cash and deposit accounts plus savings $\left(L_{i t}^{(1)}\right)$. Regarding independent variables, SIZE is the logarithm of total assets; INC is the total household net income; $L E V$ is the ratio of total household debt to total household assets; $A G E$ is the age of the eldest member of the household; $E D U$ is a dummy variable of value 1 when senior vocational education or university education is present, and zero otherwise; PENSION is a dummy variable of value 1 when a pension is present, and zero otherwise; $O W N E R$ is a dummy variable of value 1 when household owns house, and zero otherwise; and $M T G$ is a dummy variable of value 1 when household has mortgage debt, and zero otherwise; $E M P L$ is a dummy variable of value 1 when the head of the household is employed and zero otherwise; and $S E L F$ is a dummy variable of value 1 when the head of the household is self-employed and zero otherwise. The regression is estimated using OLS. Predicted coefficient signs are presented in brackets. Outputs reported are estimated coefficients, standard errors of coefficients (Std. Error), and significance level (p-value).

Model 1

Model 2

$L_{i t}^{(0)}$

Constant

$S I Z E_{i t}$

$I N C_{i t}$

$L E V_{i t}$

$A G E_{i t}$

$E D U_{i t}$

PENSION $_{i t} \quad(+)$

$O W N E R_{i t}$

$M T G_{i t} \quad(+/-)$

$E M P L_{i t}$

$S E L F_{i t}$

(+)
Std. Error p-value

$\begin{array}{rr}509.23 & 0.00 \\ 47.66 & 0.00 \\ 0.01 & 0.02 \\ 168.54 & 0.00 \\ 5.19 & 0.00 \\ 115.52 & 0.05 \\ & \end{array}$

0.08
Std. Error p-value

-8440.88
993.24
0.02
-1157.31
17.28
-244.66
539.45
-2108.39
159.09
58.51
1305.51

743.42

0.00

82.20

0.00

$\begin{array}{ll}0.01 & 0.02\end{array}$

$176.50 \quad 0.00$

$5.94 \quad 0.00$

$113.70 \quad 0.03$

$271.83 \quad 0.05$

$329.25 \quad 0.00$

$264.55 \quad 0.55$

$179.52 \quad 0.74$

$551.99 \quad 0.02$

0.10

R-Square

Std. Error p-value

$L_{i t}^{(1)}$

Constant
$S I Z E_{i t}$
$I N C_{i t}$
$L E V_{i t}$
$A G E_{i t}$
$E D U_{i t}$
$P E N S I O N_{i t}$
$O W N E R_{i t}$
$M T G_{i t}$
$E M P L_{i t}$
$S E L F_{i t}$

R-Square
Std. Error p-value

-28922.88
3600.30
0.08
-12694.67
79.47
-451.06

1900.00
175.48
0.03
736.93
22.55
462.14

0.00
$-53164.68$
6482.40

0.07

0.00

0.00

$-10298.05$

52.68

$-475.92$

2427.66

$-14433.11$

1747.06

1564.07

2105.62

$\begin{array}{rl}3647.24 & 0.00 \\ 385.53 & 0.00 \\ 0.02 & 0.00 \\ 758.08 & 0.00 \\ 24.79 & 0.03 \\ 454.35 & 0.30 \\ 940.94 & 0.01 \\ 1572.51 & 0.00 \\ 1082.20 & 0.11 \\ 652.57 & 0.02 \\ 1688.13 & 0.21\end{array}$

0.22

0.21

N. Obs.

0.19

N. Clusters

$9,957^{43}$ 
Table 3: Incremental Financing Decisions Model for $L_{i t}^{(0)}$

The table presents results for regressions 12 - -17 considering definition $L_{i t}^{(0)}$ : cash and deposit accounts. The dependent variable is $-\Delta l_{i t}$ for regression 12 , and $-\Delta l_{i t}-l_{i, t-1}$ for (13)-(17). $D_{0}$ is a dummy variable observing the value of 1 if $-\Delta w_{i t}<-\bar{l}+l_{i, t-1}$, and $D_{1}$ is a dummy variable observing the value of 1 if $-\Delta w_{i t}>l_{i, t-1}$. The regression is estimated using OLS. Outputs reported are estimated coefficients, standard errors of coefficients (in italics), and confidence intervals at the $5 \%$ level. Statistical significance is indicated by ${ }^{* * *}$ for $1 \%$ level, ${ }^{* *}$ for $5 \%$ level, and ${ }^{*}$ for $10 \%$ level.

\begin{tabular}{|c|c|c|c|c|c|c|}
\hline Equation & 12 & 13 & 14 & 15 & 16 & 17 \\
\hline \multirow{3}{*}{ Constant } & -0.019 & $-0.880^{* * *}$ & $-0.876^{* * *}$ & $-0.557^{* * *}$ & $-0.541^{* * *}$ & $-0.423^{* * *}$ \\
\hline & 0.012 & 0.019 & 0.021 & 0.020 & 0.022 & 0.027 \\
\hline & $(-0.04,0.00)$ & $(-0.92,-0.84)$ & $(-0.92,-0.84)$ & $(-0.60,-0.52)$ & $(-0.58,-0.50)$ & $(-0.48,-0.37)$ \\
\hline \multirow[t]{3}{*}{$-\Delta w_{i t}$} & $0.009^{* * *}$ & & & & & \\
\hline & 0.002 & & & & & \\
\hline & $(0.01,0.01)$ & & & & & \\
\hline \multirow[t]{3}{*}{$\min \left(-\Delta w_{i t}-l_{i, t-1}, 0\right)$} & & $0.017^{* * *}$ & & & & \\
\hline & & 0.002 & & & & \\
\hline & & $(0.01,0.02)$ & & & & \\
\hline \multirow[t]{3}{*}{$\left(-\Delta w_{i t}-l_{i, t-1}\right)$} & & & $0.017^{* * *}$ & $0.355^{* * *}$ & $0.697^{* * *}$ & $0.308^{* * *}$ \\
\hline & & & 0.002 & 0.020 & 0.039 & 0.026 \\
\hline & & & $(0.01,0.02)$ & $(0.32,0.39)$ & $(0.62,0.77)$ & $(0.26,0.36)$ \\
\hline \multirow[t]{3}{*}{$\max \left(-\Delta w_{i t}-l_{i, t-1}, 0\right)$} & & & $-0.018^{* * *}$ & $-0.366^{* * *}$ & $-0.708^{* * *}$ & $-0.315^{* * *}$ \\
\hline & & & 0.003 & 0.020 & 0.039 & 0.026 \\
\hline & & & $(-0.02,-0.01)$ & $(-0.41,-0.33)$ & $(-0.79,-0.63)$ & $(-0.37,-0.26)$ \\
\hline \multirow[t]{3}{*}{$\min \left(-\Delta w_{i t}-l_{i, t-1}+\bar{l}, 0\right)$} & & & & $-0.356^{* * *}$ & & $-0.312^{* * *}$ \\
\hline & & & & 0.020 & & 0.026 \\
\hline & & & & $(-0.40,-0.32)$ & & $(-0.36,-0.26)$ \\
\hline \multirow[t]{3}{*}{$\min \left(-\Delta w_{i t}, 0\right)$} & & & & & $-0.699^{* * *}$ & \\
\hline & & & & & 0.040 & \\
\hline & & & & & $(-0.78,-0.62)$ & \\
\hline \multirow[t]{3}{*}{$D_{0, i t}$} & & & & & & $-0.316^{* * *}$ \\
\hline & & & & & & 0.053 \\
\hline & & & & & & $(-0.42,-0.21)$ \\
\hline \multirow[t]{3}{*}{$D_{1, i t}$} & & & & & & $-0.224^{* * *}$ \\
\hline & & & & & & 0.035 \\
\hline & & & & & & $(-0.29,-0.15)$ \\
\hline R-Square & 0.009 & 0.011 & 0.011 & 0.048 & 0.258 & 0.054 \\
\hline
\end{tabular}


Table 4: Incremental Financing Decisions Model for $L_{i t}^{(1)}$

The table presents results for regressions 12 - 17 using definition $L_{i t}^{(1)}$ : cash and deposit accounts plus savings. The dependent variable is $-\Delta l_{i t}$ for regression 12 , and $-\Delta l_{i t}-l_{i, t-1}$ for 13 - 17 . $D_{0}$ is a dummy variable observing the value of 1 if $-\Delta w_{i t}<-\bar{l}+l_{i, t-1}$, and $D_{1}$ is a dummy variable observing the value of 1 if $-\Delta w_{i t}>l_{i, t-1}$. The regression is estimated using OLS. Outputs reported are estimated coefficients, standard errors of coefficients (in italics), and confidence intervals at the $5 \%$ level. Statistical significance is indicated by ${ }^{* * *}$ for $1 \%$ level, ${ }^{* *}$ for $5 \%$ level, and ${ }^{*}$ for $10 \%$ level.

\begin{tabular}{|c|c|c|c|c|c|c|}
\hline Equation & 12 & 13 & 14 & 15 & 16 & 17 \\
\hline \multirow[t]{3}{*}{ Constant } & 0.012 & $-0.629^{* * *}$ & $-0.612^{* * *}$ & $-0.219^{* * *}$ & $-0.296^{* * *}$ & $-0.129^{* * *}$ \\
\hline & 0.008 & 0.020 & 0.021 & 0.015 & 0.031 & 0.009 \\
\hline & $(-0.00,0.03)$ & $(-0.67,-0.59)$ & $(-0.65,-0.57)$ & $(-0.25,-0.19)$ & $(-0.36,-0.23)$ & $(-0.15,-0.11)$ \\
\hline \multirow[t]{3}{*}{$-\Delta w_{i t}$} & $0.098^{* * *}$ & & & & & \\
\hline & 0.008 & & & & & \\
\hline & $(0.08,0.11)$ & & & & & \\
\hline \multirow[t]{3}{*}{$\min \left(-\Delta w_{i t}-l_{i, t-1}, 0\right)$} & & $0.224^{* * *}$ & & & & \\
\hline & & 0.018 & & & & \\
\hline & & $(0.19,0.26)$ & & & & \\
\hline \multirow[t]{3}{*}{$\left(-\Delta w_{i t}-l_{i, t-1}\right)$} & & & $0.228^{* * *}$ & $0.735^{* * *}$ & $0.880^{* * *}$ & $0.761^{* * *}$ \\
\hline & & & 0.018 & 0.027 & 0.048 & 0.013 \\
\hline & & & $(0.19,0.26)$ & $(0.68,0.79)$ & $(0.79,0.97)$ & $(0.74,0.79)$ \\
\hline \multirow[t]{3}{*}{$\max \left(-\Delta w_{i t}-l_{i, t-1}, 0\right)$} & & & $-0.249^{* * *}$ & $-0.806^{* * *}$ & $-0.940^{* * *}$ & $-0.798^{* * *}$ \\
\hline & & & 0.021 & 0.030 & 0.052 & 0.014 \\
\hline & & & $(-0.29,-0.21)$ & $(-0.86,-0.74)$ & $(-1.04,-0.84)$ & $(-0.83,-0.77)$ \\
\hline \multirow[t]{3}{*}{$\min \left(-\Delta w_{i t}-l_{i, t-1}+\bar{l}, 0\right)$} & & & & $-0.739^{* * *}$ & & $-0.795^{* * *}$ \\
\hline & & & & 0.060 & & 0.047 \\
\hline & & & & $(-0.86,-0.62)$ & & $(-0.89,-0.70)$ \\
\hline \multirow[t]{3}{*}{$\min \left(-\Delta w_{i t}, 0\right)$} & & & & & $-0.843^{* * *}$ & \\
\hline & & & & & 0.048 & \\
\hline & & & & & $(-0.94,-0.75)$ & \\
\hline \multirow[t]{3}{*}{$D_{0, i t}$} & & & & & & $-0.175^{* *}$ \\
\hline & & & & & & 0.083 \\
\hline & & & & & & $(-0.34,-0.01)$ \\
\hline \multirow[t]{3}{*}{$D_{1, i t}$} & & & & & & $-0.356^{* * *}$ \\
\hline & & & & & & 0.024 \\
\hline & & & & & & $(-0.40,-0.31)$ \\
\hline R-Square & 0.092 & 0.168 & 0.170 & 0.302 & 0.551 & 0.316 \\
\hline
\end{tabular}




\section{Table 5: Incremental Financing Decisions Model for Different Values of $\bar{l}$}

The table presents results for regressions 15 and 17 using definition $L_{i t}^{(1)}$ : cash and deposit accounts plus savings accounts, and different values of $\bar{l} . \bar{l}$ equals 2 for a symmetric distribution of liquidity. $\bar{l}=2.6$ maximises the fit of model $[15$. $\bar{l}=3.1$ maximises the fit of model 17. The dependent variable is $-\Delta l_{i t}-l_{i, t-1}$. $D_{0}$ is a dummy variable observing the value of 1 if $-\Delta w_{i t}<-\bar{l}+l_{i, t-1}$, and $D_{1}$ is a dummy variable observing the value of 1 if $-\Delta w_{i t}>l_{i, t-1}$. The regression is estimated using OLS. Outputs reported are estimated coefficients, standard errors of coefficients (in italics), and confidence intervals at the $5 \%$ level. Statistical significance is indicated by ${ }^{* * *}$ for $1 \%$ level, ${ }^{* *}$ for $5 \%$ level, and ${ }^{*}$ for $10 \%$ level.

\begin{tabular}{|c|c|c|c|c|c|c|}
\hline \multirow[t]{2}{*}{ Equation } & 15 & 15 & 15 & 17 & 17 & 17 \\
\hline & $\bar{l}=2$ & $\bar{l}=2.6$ & $\bar{l}=3.1$ & $\bar{l}=2$ & $\bar{l}=2.6$ & $\bar{l}=3.1$ \\
\hline \multirow[t]{3}{*}{ Constant } & $-0.219^{* * *}$ & $-0.263^{* * *}$ & $-0.305^{* * *}$ & $-0.129^{* * *}$ & $-0.158^{* * *}$ & $-0.174^{* * *}$ \\
\hline & 0.060 & 0.067 & 0.075 & 0.047 & 0.059 & 0.070 \\
\hline & $(-0.25,-0.19)$ & $(-0.29,-0.23)$ & $(-0.34,-0.27)$ & $(-0.15,-0.11)$ & $(-0.18,-0.14)$ & $(-0.19,-0.15)$ \\
\hline \multirow[t]{3}{*}{$\left(-\Delta w_{i t}-l_{i, t-1}\right)$} & $0.735^{* * *}$ & $0.638^{* * *}$ & $0.569^{* * *}$ & $0.761^{* * *}$ & $0.715^{* * *}$ & $0.692^{* * *}$ \\
\hline & 0.027 & 0.025 & 0.024 & 0.013 & 0.013 & 0.014 \\
\hline & $(0.68,0.79)$ & $(0.59,0.69)$ & $(0.52,0.62)$ & $(0.74,0.79)$ & $(0.69,0.74)$ & $(0.66,0.72)$ \\
\hline \multirow[t]{3}{*}{$\max \left(-\Delta w_{i t}-l_{i, t-1}, 0\right)$} & $-0.806^{* * *}$ & $-0.702^{* * *}$ & $-0.628^{* * *}$ & $-0.798^{* * *}$ & $-0.752^{* * *}$ & $-0.728^{* * *}$ \\
\hline & 0.030 & 0.028 & 0.027 & 0.014 & 0.014 & 0.015 \\
\hline & $(-0.86,-0.75)$ & $(-0.76,-0.65)$ & $(-0.68,-0.58)$ & $(-0.83,-0.77)$ & $(-0.80,-0.72)$ & $(-0.76,-0.70)$ \\
\hline \multirow[t]{3}{*}{$\min \left(-\Delta w_{i t}-l_{i, t-1}+\bar{l}, 0\right)$} & $-0.739^{* * *}$ & $-0.700^{* * *}$ & $-0.669^{* * *}$ & $-0.795^{* * *}$ & $-0.776^{* * *}$ & $-0.737^{* * *}$ \\
\hline & 0.060 & 0.067 & 0.075 & 0.047 & 0.059 & 0.070 \\
\hline & $(-0.86,-0.62)$ & $(-0.83,-0.57)$ & $(-0.82,-0.52)$ & $(-0.88,-0.70)$ & $(-0.89,-0.66)$ & $(-0.86,-0.60)$ \\
\hline \multirow[t]{3}{*}{$D_{0, i t}$} & & & & $-0.175^{* *}$ & 0.102 & $0.505^{* * *}$ \\
\hline & & & & 0.083 & 0.114 & 0.138 \\
\hline & & & & $(-0.34,-0.01)$ & $(-0.12,0.32)$ & $(0.23,0.78)$ \\
\hline \multirow[t]{3}{*}{$D_{1, i t}$} & & & & $-0.356^{* * *}$ & $-0.328^{* * *}$ & $-0.312^{* * *}$ \\
\hline & & & & 0.024 & 0.024 & 0.025 \\
\hline & & & & $(-0.40,-0.31)$ & $(-0.37,-0.28)$ & $(-0.36,-0.26)$ \\
\hline R-Square & 0.302 & 0.309 & 0.304 & 0.316 & 0.318 & 0.318 \\
\hline
\end{tabular}


Table 6: Determinants of the Probability and the Magnitude of Overdrafts The table presents results of a probit model of the determinants of the probability of an overdraft, and results of a tobit model of the determinants of the magnitude of an overdraft. The second column presents the expected signs of model coefficients. All explanatory variables are defined in section 5.3 Outputs reported are estimated coefficients, marginal effects, standard errors of coefficients (in italics), and p-values.

\begin{tabular}{|c|c|c|c|c|}
\hline & \multirow{2}{*}{$\begin{array}{l}\text { Predicted } \\
\text { sign }\end{array}$} & \multicolumn{2}{|c|}{ Probit model } & \multirow{2}{*}{$\begin{array}{r}\text { Tobit model } \\
\text { Coeff }\end{array}$} \\
\hline & & Coeff. & Marg. effect & \\
\hline \multirow[t]{3}{*}{ Constant } & & -1.441 & & -45756.92 \\
\hline & & 0.305 & & 5159.01 \\
\hline & & 0.000 & & 0.000 \\
\hline \multirow[t]{3}{*}{$S I Z E_{i t}$} & $(-)$ & -0.063 & -0.008 & -440.67 \\
\hline & & 0.027 & 0.003 & 502.95 \\
\hline & & 0.020 & 0.018 & 0.381 \\
\hline \multirow[t]{3}{*}{$I N C_{i t}$} & $(-)$ & -0.000 & -0.000 & 0.004 \\
\hline & & 0.000 & 0.000 & 0.017 \\
\hline & & 0.727 & 0.727 & 0.804 \\
\hline \multirow[t]{3}{*}{$L E V_{i t}$} & $(+)$ & 0.826 & 0.101 & 19580.19 \\
\hline & & 0.073 & 0.010 & 1401.48 \\
\hline & & 0.000 & 0.000 & 0.000 \\
\hline \multirow[t]{3}{*}{$A G E_{i t}$} & $(+)$ & 0.004 & 0.001 & 135.55 \\
\hline & & 0.003 & 0.000 & 44.82 \\
\hline & & 0.119 & 0.122 & 0.002 \\
\hline \multirow[t]{3}{*}{$E D U_{i t}$} & $(-)$ & 0.069 & 0.009 & 933.31 \\
\hline & & 0.053 & 0.007 & 905.60 \\
\hline & & 0.193 & 0.200 & 0.303 \\
\hline \multirow[t]{3}{*}{ PENSION } & $(+/-)$ & -0.155 & -0.018 & -356.33 \\
\hline & & 0.095 & 0.010 & 1583.03 \\
\hline & & 0.104 & 0.076 & 0.822 \\
\hline \multirow[t]{3}{*}{$O W N E R_{i t}$} & $(+/-)$ & 0.090 & 0.011 & 1470.95 \\
\hline & & 0.127 & 0.015 & 2280.06 \\
\hline & & 0.475 & 0.463 & 0.519 \\
\hline \multirow[t]{3}{*}{$M T G_{i t}$} & $(+/-)$ & 0.007 & 0.001 & -1156.31 \\
\hline & & 0.099 & 0.012 & 1662.88 \\
\hline & & 0.945 & 0.945 & 0.487 \\
\hline \multirow[t]{3}{*}{$S E L F_{i t}$} & $(+/-)$ & 0.335 & 0.052 & 7206.43 \\
\hline & & 0.116 & 0.022 & 2135.49 \\
\hline & & 0.004 & 0.018 & 0.001 \\
\hline \multirow[t]{3}{*}{$U N E M P L_{i t}$} & $(+)$ & 0.694 & 0.136 & 14042.26 \\
\hline & & 0.180 & 0.050 & 2687.95 \\
\hline & & 0.000 & 0.006 & 0.000 \\
\hline \multirow[t]{3}{*}{$B E N E F I T_{i t}$} & $(+)$ & 0.085 & 0.010 & 590.55 \\
\hline & & 0.051 & 0.006 & 889.85 \\
\hline & & 0.095 & 0.096 & 0.507 \\
\hline \multirow[t]{3}{*}{$K I D S_{i t}$} & $(+/-)$ & 0.078 & 0.010 & 1684.63 \\
\hline & & 0.026 & 0.003 & 413.39 \\
\hline & & 0.002 & 0.002 & 0.000 \\
\hline R-Square & & 0.0674 & & 0.016 \\
\hline
\end{tabular}


Table 7: Augmented Incremental Financing Decisions Model

The table presents results for augmented regression 17 using definition $L_{i t}^{(1)}$ : cash and deposit accounts plus savings. The dependent variable is $-\Delta l_{i t}-l_{i, t-1}$. $D_{0}$ is a dummy variable equal to 1 if $-\Delta w_{i t}<-\bar{l}+l_{i, t-1}$ and 0 otherwise, and $D_{1}$ is a dummy variable equal to 1 if $-\Delta w_{i t}>l_{i, t-1}$ and 0 otherwise. $X_{i t}$ corresponds to the dummy variable stated at the top of each column. The regression is estimated using OLS. Outputs reported are estimated coefficients, standard errors of coefficients (in italics), and confidence intervals at the $5 \%$ level. Statistical significance is indicated by ${ }^{* *}$ for $1 \%$ level, ${ }^{* *}$ for $5 \%$ level, and ${ }^{*}$ for $10 \%$ level.

OVERDRAFT INCL SIZEL LEVH AGEH BENEFIT $\quad$ UNEMPL

\begin{tabular}{|c|c|c|c|c|c|c|c|}
\hline \multirow[t]{3}{*}{ Constant } & $-0.174^{* * *}$ & $-0.194^{* * *}$ & $-0.190^{* * *}$ & $-0.150 * * *$ & $-0.178^{* * *}$ & $-0.226^{* * *}$ & $-0.174^{* * *}$ \\
\hline & 0.011 & 0.016 & 0.015 & 0.013 & 0.015 & 0.015 & 0.011 \\
\hline & $(-0.19,-0.15)$ & $(-0.23,-0.16)$ & $(-0.22,-0.16)$ & $(-0.18,-0.13)$ & $(-0.21,-0.15)$ & $(-0.26,-0.20)$ & $(-0.20,-0.15)$ \\
\hline \multirow[t]{3}{*}{$\min \left(-\Delta w_{i t}-l_{i, t-1}+\bar{l}, 0\right)$} & $-0.745^{* * *}$ & $-0.813^{* * *}$ & $-0.879^{* * *}$ & $-0.886^{* * *}$ & $-0.649^{* * *}$ & $-0.578^{* * *}$ & $-0.735^{* * *}$ \\
\hline & 0.073 & 0.063 & 0.030 & 0.031 & 0.102 & 0.105 & 0.071 \\
\hline & $(-0.89,-0.60)$ & $(-0.94,-0.69)$ & $(-0.94,-0.82)$ & $(-0.95,-0.83)$ & $(-0.85,-0.45)$ & $(-0.78,-0.37)$ & $(-0.87,-0.60)$ \\
\hline \multirow[t]{3}{*}{$\left(-\Delta w_{i t}-l_{i, t-1}\right)$} & $0.706^{* * *}$ & $0.697^{* * *}$ & $0.698^{* * *}$ & $0.714^{* * *}$ & $0.682^{* * *}$ & $0.613^{* * *}$ & $0.693^{* * *}$ \\
\hline & 0.014 & 0.017 & 0.017 & 0.018 & 0.020 & 0.020 & 0.014 \\
\hline & $(0.68,0.73)$ & $(0.66,0.73)$ & $(0.66,0.73)$ & $(0.68,0.75)$ & $(0.64,0.72)$ & $(0.57,0.65)$ & $(0.67,0.72)$ \\
\hline \multirow[t]{3}{*}{$\max \left(-\Delta w_{i t}-l_{i, t-1}, 0\right)$} & $-0.741^{* * *}$ & $-0.738^{* * *}$ & $-0.730^{* * *}$ & $-0.788^{* * *}$ & $-0.715^{* * *}$ & $-0.653^{* * *}$ & $-0.729^{* * *}$ \\
\hline & 0.015 & 0.019 & 0.019 & 0.035 & 0.022 & 0.021 & 0.015 \\
\hline & $(-0.77,-0.71)$ & $(-0.78,-0.70)$ & $(-0.77,-0.69)$ & $(-0.86,-0.72)$ & $(-0.76,-0.67)$ & $(-0.70,-0.61)$ & $(-0.76,-0.70)$ \\
\hline \multirow[t]{3}{*}{$D_{0, i t}$} & $0.491^{* * *}$ & $0.314^{* *}$ & 0.052 & $0.457^{* * *}$ & $0.736^{* * *}$ & $0.753^{* * *}$ & $0.517^{* * *}$ \\
\hline & 0.142 & 0.127 & 0.096 & 0.098 & 0.217 & 0.205 & 0.139 \\
\hline & $(0.21,0.77)$ & $(0.064,0.563)$ & $(-0.14,0.24)$ & $(0.27,0.65)$ & $(0.31,1.16)$ & $(0.35,1.16)$ & $(0.25,0.79)$ \\
\hline \multirow[t]{3}{*}{$D_{1, i t}$} & $-0.381^{* * *}$ & $-0.353^{* * *}$ & $-0.365^{* * *}$ & $-0.218^{* * *}$ & $-0.327^{* * *}$ & $-0.245^{* * *}$ & $-0.316^{* * *}$ \\
\hline & 0.027 & 0.035 & 0.035 & 0.040 & 0.031 & 0.030 & 0.025 \\
\hline & $(-0.43,-0.33)$ & $(-0.42,-0.28)$ & $(-0.43,-0.30)$ & $(-0.30,-0.14)$ & $(-0.39,-0.27)$ & $(-0.30,-0.19)$ & $(-0.36,-0.27)$ \\
\hline \multirow[t]{3}{*}{$\min \left(-\Delta w_{i t}-l_{i, t-1}+\bar{l}, 0\right) * X_{i t}$} & $0.318^{* * *}$ & 0.182 & $0.337^{* *}$ & $0.324^{* *}$ & $-0.222^{* *}$ & $-0.329^{* *}$ & -0.210 \\
\hline & 0.112 & 0.144 & 0.138 & 0.135 & 0.109 & 0.129 & 0.185 \\
\hline & $(0.10,0.54)$ & $(-0.10,-0.46)$ & $(0.07,0.61)$ & $(0.06,0.59)$ & $(0.44,-0.01)$ & $(-0.58,-0.08)$ & $(-0.57,0.15)$ \\
\hline \multirow[t]{3}{*}{$\left(-\Delta w_{i t}-l_{i, t-1}\right) * X_{i t}$} & $-0.375^{* * *}$ & -0.020 & -0.023 & $-0.052^{*}$ & 0.018 & $0.155^{* * *}$ & -0.083 \\
\hline & 0.058 & 0.026 & 0.027 & 0.027 & 0.027 & 0.025 & 0.090 \\
\hline & $(-0.49,-0.26)$ & $(-0.07,0.03)$ & $(-0.08,0.03)$ & $(-0.11,0.00)$ & $(-0.03,0.07)$ & $(0.11,0.20)$ & $(-0.26,0.09)$ \\
\hline \multirow[t]{3}{*}{$\max \left(-\Delta w_{i t}-l_{i, t-1}, 0\right) * X_{i t}$} & $0.388^{* * *}$ & 0.034 & 0.014 & $0.095^{* *}$ & -0.027 & $-0.147^{* * *}$ & 0.091 \\
\hline & 0.060 & 0.029 & 0.029 & 0.041 & 0.030 & 0.028 & 0.093 \\
\hline & $(0.27,0.51)$ & $(-0.02,0.09)$ & $(-0.04,0.07)$ & $(0.01,0.18)$ & $(-0.09,0.03)$ & $(-0.20,-0.09)$ & $(-0.09,0.27)$ \\
\hline \multirow[t]{3}{*}{$D_{0, i t} * X_{i t}$} & -0.018 & 0.433 & $1.089^{* * *}$ & 0.043 & $-0.512^{* *}$ & $-0.603^{* *}$ & -1.113 \\
\hline & 0.285 & 0.287 & 0.277 & 0.275 & 0.242 & 0.254 & 0.825 \\
\hline & $(-0.58,0.54)$ & $(-0.13,1.00)$ & $(0.55,1.63)$ & $(-0.50,0.58)$ & $(-0.99,-0.04)$ & $(-1.10,-0.10)$ & $(-2.73,0.50)$ \\
\hline \multirow[t]{3}{*}{$D_{1, i t} * X_{i t}$} & $0.417^{* * *}$ & $0.106^{* *}$ & $0.145^{* * *}$ & $-0.099^{* *}$ & 0.039 & $-0.136^{* * *}$ & $0.292^{* * *}$ \\
\hline & 0.057 & 0.047 & 0.047 & 0.050 & 0.049 & 0.048 & 0.081 \\
\hline & $(0.31,0.53)$ & $(0.01,0.20)$ & $(0.05,0.24)$ & $(-0.20,-0.00)$ & $(-0.06,0.13)$ & $(-0.23,-0.04)$ & $(0.13,0.45)$ \\
\hline \multirow[t]{3}{*}{$X_{i t}$} & -0.018 & 0.030 & 0.020 & $-0.055^{* *}$ & 0.008 & $0.100^{* * *}$ & 0.019 \\
\hline & 0.042 & 0.021 & 0.021 & 0.022 & 0.021 & 0.020 & 0.065 \\
\hline & $(-0.10,0.06)$ & $(-0.01,0.07)$ & $(-0.22,0.06)$ & $(-0.10,-0.01)$ & $(-0.03,0.05)$ & $(0.06,0.14)$ & $(-0.11,0.15)$ \\
\hline R-Square & 0.340 & 0.326 & 0.343 & 0.337 & 0.326 & 0.338 & 0.320 \\
\hline
\end{tabular}

